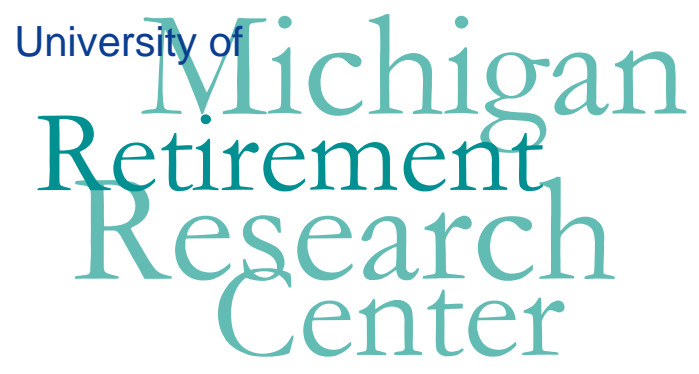

Working Paper

WP 2006-113

\title{
The Effect of Unfolding Brackets on the Quality of Wealth Data in HRS
}

F. Thomas Juster, Honggao Cao, Michael Perry, and Mick Couper

\begin{tabular}{|l|l|l|l|l}
\hline $\mathrm{M}$ & $\mathrm{R}$ & Project \#: UM05-06 \\
\hline & $\mathrm{C}$ & $\mathrm{C}$
\end{tabular} 


\title{
“The Effect of Unfolding Brackets on the Quality of Wealth Data in HRS"
}

\author{
F. Thomas Juster \\ University of Michigan \\ Honggao Cao \\ University of Michigan \\ Michael Perry \\ University of Michigan \\ Mick Couper \\ University of Michigan \\ January 2006 \\ Michigan Retirement Research Center \\ University of Michigan \\ P.O. Box 1248 \\ Ann Arbor, MI 48104 \\ http://www.mrrc.isr.umich.edu/ \\ (734) 615-0422
}

\section{Acknowledgements}

This work was supported by a grant from the Social Security Administration through the Michigan Retirement Research Center (Grant \# 10-P-98358-5). The findings and conclusions expressed are solely those of the author and do not represent the views of the Social Security Administration, any agency of the Federal government, or the Michigan Retirement Research Center.

\section{Regents of the University of Michigan}

David A. Brandon, Ann Arbor; Laurence B. Deitch, Bingham Farms; Olivia P. Maynard, Goodrich; Rebecca McGowan, Ann Arbor; Andrea Fischer Newman, Ann Arbor; Andrew C. Richner, Grosse Pointe Park; S. Martin Taylor, Gross Pointe Farms; Katherine E. White, Ann Arbor; Mary Sue Coleman, ex officio 


\title{
The Effect of Unfolding Brackets on the Quality of Wealth Data in HRS
}

\author{
F. Thomas Juster, Honggao Cao, Michael Perry, and Mick Couper
}

\begin{abstract}
A characteristic feature of survey data on household wealth is the high incidence of missing data — roughly one in three respondents who report owning an asset are unable or unwilling to provide an estimate of the exact amount of their holding. A partial solution to that problem is to devise a series of questions that put the respondent's holdings into a quantitative range (less than $\mathrm{x}$, more than $\mathrm{x}$, or what?). These quantitative ranges are called unfolding brackets, and they represent a survey innovation that aims to improve the quality of wealth data by substituting range data for completely missing data. In this paper, we examine the effect of unfolding brackets on the quality of HRS wealth data. Special attention is given to the impact of unfolding bracket entry points on the distribution of asset holdings in HRS 1998. Although there is a small positive relationship between mean asset holdings and entry point, there are many cases where that relationship does not hold. In general, our conclusion is that entry point bias problems are not a major concern in the evaluation of quality in the 1998 HRS wealth data.
\end{abstract}

\section{Authors’ Acknowledgements}

We thank Daniel H. Hill for his suggestions relating to work done at the early stage of this project. All errors are our own. 


\section{The Effect of Unfolding Brackets on the Quality of Wealth Data in HRS}

\section{Overview}

One of the major innovations of the Health and Retirement Study (HRS) is the addition of an unfolding bracket question sequence for those respondents who own an asset but who are unwilling or unable to provide an estimate of the amount. (See Appendix 1 for the basic structure of an unfolding bracket question sequence.) The unfolding brackets idea originated in the wealth module of the Panel Study of Income Dynamics (PSID) in 1984, when a very short wealth sequence was first asked in an ISR/SRC survey. It turns out that the missing data rate (the R owns an asset but is not willing or able to provide a dollar amount) is very sizeable in both HRS and AHEAD—-much larger than had proved to be the case for PSID. The typical missing data rate in the HRS and AHEAD studies is of the order of the low thirty percent, a missing data rate that can be reduced to mainly single digits by using the unfolding bracket question sequence.

If it were the case that respondents who did not or could not provide point estimates of their asset holdings (or of other financial flows) did not behave differently, relative to demographic and other characteristics, than respondents who provided point estimates (continuous data cases), then how the missing data cases are treated would make relatively little difference. There would be no systematic bias associated with respondents placing themselves in an unfolding bracket category rather than reporting an exact data number. But if it turned out that missing data cases had values that were systematically high or low relative to personal characteristics of the respondent, then taking that into account might well make a substantial difference in estimates of the distribution of asset holdings, or in the mean levels of such holdings. It would be quite important to find an estimate of the size of that bias and to correct the data for it. In effect, if the imputation program used to convert missing data to imputed data 
produces the result that there is no systematic difference between continuous (exact) data and missing data, then the gains from using unfolding brackets would be miniscule. On the other hand, if it turned out that missing data cases were systematically very different than continuous data cases, then developing a proper imputation program that corrects for that bias would be quite important.

Initial exploration of this problem produced the not unexpected result that missing data cases were in fact quite different than continuous data cases, and that the appropriate adjustment would involve a substantial increase in the level of asset holdings. Two early papers made this point clearly. One was a paper by Juster and Smith, published in JASA in 1997, which adopted the strategy of imputing missing data cases by random draws from the bracket category that respondents placed themselves into. That is, if a respondent said that their asset holdings were more than $\$ 5000$ but less than $\$ 50,000$, an estimate of the respondent's holdings could be calculated by making a random draw from continuous data cases located in that particular bracket category—in this case, in the category $\$ 5000$ to $\$ 50,000$. Roughly the same results were obtained in another study, authored by Hurd and published in the Journal of Risk and Uncertainty in 1999. Both of these studies used data collected in Wave 1 of HRS and Wave 1 of AHEAD; the Hurd study also used Wave 2 HRS data.

Table 1 below shows the results of the imputations from these two studies. The top panel has mean values for each category of HRS 1992 asset holdings, while the second panel has HRS 1992 median values. The third panel has 1994 HRS data. The column labeled "RAND-H” represents work done on the imputation of asset holdings by RAND staff working with Hurd, while the category labeled "RAND-S" represents work done by RAND staff working with Smith. 


\section{Table 1}

The Impact of Unfolding Brackets on Estimates of the Level and Distribution of Wealth

\begin{tabular}{|c|c|c|c|c|c|c|}
\hline \multicolumn{7}{|c|}{ A. Mean Values, HRS Wave 1 Data (000) } \\
\hline \multirow[b]{2}{*}{ Asset Component } & \multicolumn{3}{|c|}{$\underline{\mathrm{RAND}-\mathrm{H}^{\mathrm{a}}}$} & \multicolumn{3}{|c|}{ RAND-S $^{b}$} \\
\hline & Continuous & Bracket & Bracket $\Delta$ & Continuous & Bracket & Bracket $\Delta$ \\
\hline Real Estate & 149 & 219 & +70 & 129 & 222 & +93 \\
\hline Business/Farm & 168 & 294 & +126 & 166 & 349 & +183 \\
\hline IRAs & 45 & 45 & 0 & 44 & 56 & +12 \\
\hline Stock & 59 & 73 & +14 & 57 & 74 & +17 \\
\hline Bonds & 48 & 73 & +25 & 47 & 68 & +21 \\
\hline Ck/Saving/MM & 16 & 21 & +5 & 16 & 23 & +7 \\
\hline CDs, T-Bills & 27 & 45 & +18 & 27 & 48 & +21 \\
\hline Transportation & 13 & 22 & +9 & 13 & 18 & +5 \\
\hline \multicolumn{7}{|c|}{ B: Median Values, HRS Wave 1 Data (000) } \\
\hline & \multicolumn{3}{|c|}{$\underline{\text { RAND-H }}$} & \multicolumn{3}{|c|}{ RAND-S } \\
\hline Asset Component & Continuous & Bracket & Bracket $\Delta$ & Continuous & Bracket & Bracket $\Delta$ \\
\hline Real Estate & 45 & 75 & +30 & 42 & 70 & +28 \\
\hline Business/Farm & 25 & 95 & +70 & 24 & 98 & +74 \\
\hline IRAs & 20 & 25 & +5 & 20 & 30 & +10 \\
\hline Stock & 18 & 20 & +2 & 17 & 23 & +6 \\
\hline Bonds & 12 & 20 & +8 & 14 & 24 & +10 \\
\hline Ck/Saving/MM & 5 & 5 & 0 & 5 & 7 & +2 \\
\hline CDs, T-Bills & 8 & 10 & +2 & 10 & 10 & 0 \\
\hline Transportation & 7 & 10 & +3 & 8 & 10 & +2 \\
\hline \multicolumn{7}{|c|}{ C: HRS Wave 2 RAND-H Data (000) } \\
\hline & \multicolumn{3}{|c|}{ Median } & \multicolumn{3}{|c|}{ Mean } \\
\hline Asset Component & Continuous & Bracket & Bracket $\Delta$ & Continuous & Bracket & Bracket $\Delta$ \\
\hline Real Estate & 50 & 90 & +40 & 98 & 229 & +131 \\
\hline Business/Farm & 55 & 75 & +20 & 112 & 197 & +82 \\
\hline IRAs & 28 & 30 & +2 & 55 & 60 & +5 \\
\hline Stock & 26 & 25 & -1 & 66 & 74 & +8 \\
\hline Bonds & 20 & 20 & 0 & 69 & 69 & 0 \\
\hline Ck/Saving/MM & 5 & 10 & +5 & 16 & 30 & +14 \\
\hline CDs, T-Bills & 8 & 20 & +12 & 24 & 64 & +40 \\
\hline Transportation & 8 & 10 & +2 & 12 & 18 & +6 \\
\hline
\end{tabular}

a) From Michael D. Hurd, "Anchoring and Acquiescence Bias in Measuring Assets in Household Surveys," Journal of Risk and Uncertainty, 1999.

b) From Juster and Smith, "Improving the Quality of Economic Data: Lessons from the HRS and AHEAD," JASA, 1997. 
Looking at the values in Table 1, it is quite clear that there is virtually no difference in the mean or median values for the categories labeled RAND-H and those labeled RAND-S. In all cases bracketed data cases yield a significantly higher mean and median value than continuous data cases, while the RAND-H and RAND-S estimates are essentially identical. The small differences that exist between the RAND-H data and the RAND-S data are probably due to the fact that the work done by Hurd treats Range Card cases as if they were continuous data cases, while the work done by Juster and Smith treats these cases as if they were unfolding bracket cases. This difference in treatment produces slightly higher values for RAND-H than for RAND$\mathrm{S}$ because the Range Cards have substantially more detail in the highest categories than do the unfolding brackets—as a consequence, imputation using random draws is likely to produce a few very high values for the Range Card cases, and thus a higher mean.

It might be useful to spell out exactly why there are a set of cases derived from Range Cards in a study where the missing data estimates are basically derived from unfolding brackets. The reason that there are Range Card cases in this study is that the original HRS design was based on measures developed for the PSID. In the PSID, housing values are asked about before either assets or income, and missing data on housing values was obtained from Range Cards rather than from unfolding brackets. ${ }^{1}$ Since the 1992 HRS survey was a personal interview survey, it was feasible to use a Range Card for missing data cases on house value. Thus the respondent had physical control of the Range Card while the housing section was being administered, and some respondents continued to use the Range Card when the survey shifted to other forms of assets. Of the roughly $30 \%$ of cases with missing data that had to be imputed,

\footnotetext{
${ }^{1}$ The Range Card that is used for both the HRS and the PSID consisted of 10 categories denoted by a letter (A through J), with amount categories as follows: $A=$ Less Than $\$ 500, B=\$ 500-1000, C=\$ 1001-2500, D=\$ 2501$ 10,000, $\mathrm{E}=\$ 10,001-50,000, \mathrm{~F}=\$ 50,001-250,000, \mathrm{G}=\$ 250,001-999,999, \mathrm{H}=\$ 1$ Million $-\$ 9,999,999, \mathrm{I}=\$ 10$ Million - \$100 Million, $\mathrm{J}=$ More than $\$ 100$ Million.
} 
roughly six percentage points are cases where Range Cards were used rather than the unfolding bracket sequence. The Hurd paper uses these Range Card cases after converting them to continuous data cases (using random draws of continuous data cases falling in each of the specific Range Card categories).

There are other characteristics of the bracket data than need to be taken into account in any imputation process, and these seem to have been handled somewhat differently in the Juster and Smith paper than in the Hurd paper. For example, it is unambiguously clear that missing data cases that represent refusals (REF) are really quite different than missing data cases where respondents say they don't know (DK). One major difference is that REF cases show a different distribution among bracket categories than DK cases, and the imputation process produces substantially higher mean and median values for REF cases than for DK cases. ${ }^{2}$ Another major difference is that REF cases typically do not complete the unfolding bracket sequences but continue to refuse, while the DK cases generally go through the unfolding bracket sequence. ${ }^{3}$

\section{Unfolding Bracket Bias}

In recent years, analysis of the unfolding bracket categories and their relationship to the continuous data category has undergone a substantial change. What has basically taken place is that some researchers have become persuaded that various types of potential biases in the treatment of unfolding bracket cases need to be corrected if the data are to be regarded as unbiased (Hurd, 1999; Soest and Hurd, 2003). The kinds of considerations that these researchers

\footnotetext{
${ }^{2}$ This analysis is based on REF or DK cases where the original response was a DK or REF, but the response to the next (bracket) question was one of the bracket categories. That is, if a DK or REF response was followed by the selection of a bracket category, the imputation was based on a random draw from continuous data cases falling into that bracket category. Cases where the only response is a DK or REF are imputed by selecting a random draw from cases where there is both a DK or REF response and a subsequent bracket selection.

${ }^{3}$ About $40 \%$ of REF cases are followed by a bracket response, while about $90 \%$ of DK cases are followed by a bracket response.
} 
worry about are known as "entry point” or "anchoring” bias, or as "acquiescence” bias. The entry point phenomenon is basically concerned with what difference it makes where the unfolding bracket categories are entered--on the low side (e.g., "is it less than $\$ 2500$, greater than \$2500, or what?"), on the high side (e.g., "is it less than half a million, more than half a million, or what?”), or somewhere in the middle (e.g., “is it less than $\$ 125,000$, more than $\$ 125,000$, or what?”). Depending on where the respondent enters into this bracket sequence, entry point bias would mean that the distribution of responses would be shifted toward the initial entry point. That is, if the initial entry point is the lowest possible bracket category, the true distribution of assets will be higher than the imputed distribution because the question sequence will generate a bias in the direction of the entry point.

The second type of bias, acquiescence bias, is associated with a respondent preference to agree with the way the question is framed by the survey designer—e.g., is it more than $\$ 25,000$ ? More than $\$ 50,000$ ? In this type of question sequence, one possible answer is “yes”, and it is widely thought that questions of that type produce biased responses because respondents are more apt to say "yes” than not to say “yes”- - yea-saying bias. We do not examine acquiescence bias in this paper because the question wording was changed in HRS 1996 to a balanced version that eliminated the possibility of acquiescence bias (e.g., is it less than $\mathrm{x}$, more than $\mathrm{x}$, or what?).

There are some characteristics of entry point bias that represent what seem to us puzzling features of the data. The theory underlying the psychology that generates these types of biases is that the way the question is framed will influence the way the question is answered. A number of well known and highly regarded papers by Kahneman and Tversky (e.g., Tversky and Kahneman, 1974, 1981; and Kahneman and Tversky, 1986) examine this framing bias. It must be the case that this type of bias is much more important, and clearly more common, when we 
are dealing with questions that the respondent does not or may not know the answer to. For example, it is not difficult to understand why there might be an entry point bias if the survey question was something like: "How many African tribes are there in the continent of Africa?” and if the respondent said “don’t know”, that question might be followed by one that said: “Are there more than 50 such tribes, less than 50 such tribes, or what?” Since the interviewer, and the respondent, can be presumed to know absolutely nothing about the true number of tribes in the continent of Africa, it would not be surprising if there were substantial bias in favor of producing a number that was close to the number specified in the question, on the grounds that the questionnaire designer knew what was a foolish question and what was not, while the respondent didn't know either and was best off relying on the implicit judgment of the interviewer and the question designer.

But what if the question, as in the case of HRS and AHEAD, has to do with checking, saving, or money market accounts, which the respondent must know quite a lot about, but may not be perfectly certain about the exact amounts in those accounts? It is hard to believe that respondents who say they own checking accounts, saving accounts, or money market accounts, wouldn't know approximately the amount of assets in those accounts—whether the accounts add up to “more than $\$ 50,000$, less than $\$ 50,000$, or what?” The major difficulty in answering this question is very likely to be that the respondent doesn’t know how to interpret “accounts”. Over the last decades or so, there has been a veritable explosion of financial instruments that have an accounts flavor, and a typical respondent who has a large number of such accounts might be unclear about which ones should be counted and which ones should be ignored. ${ }^{4}$

\footnotetext{
${ }^{4}$ There must be many households where the answer to this question is simple and straightforward and where the entry point makes absolutely no difference. Take a household that owns only a single checking account, has no saving accounts, no money market accounts, and no other assets. Is it really plausible to suppose that it matters whether the first question in the sequence asks whether such an account adds to up to less or more than $\$ 1000$, the
} 
How difficult is it to demonstrate that there really is entry point bias, and that this bias needs to be taken care of before the data can be shown to be an unbiased representation of the true distribution of assets? The idea of entry point bias, as noted above, is that low entry points produce estimates of amounts that are biased downward, high entry points produce estimates of amounts that are biased upward, and entry points in the middle produce estimates that have relatively modest bias. If that were the case, one would expect to find that the mean value of assets of a particular type should be increased from entry point one (on the low side) and entry point two (in the middle), and there should also be increases in the mean value of assets when moving from entry point two (in the middle) to entry point three (on the high side). That is, entry point bias basically says that the respondent will be moved toward the entry point in responding to any question about assets where the respondent lacks perfect certainty about the amount. Finally, picking an entry point around the mean or median may well give better results than picking an entry point at either end of the distribution.

\section{Entry Point Bias: The Empirical Evidence}

There have been enough data generated by a variety of entry point experiments in both the HRS and AHEAD survey designs so that we can look at the actual results of entry point differences. Entry point bias ought to mean that going from entry point one (low) to entry point two (higher than entry point one) would show an increase in the mean, and going from entry point two to entry point three (highest) would also show an increase in mean value. If, on the other hand, entry point bias is not present, we should find that the difference in means between entry points

next question asks about less or more than $\$ 25,000$, and the third question asks about less or more than $\$ 125,000$ ? It is hard to see why an estimate of the amount in the respondent's checking account is going to be affected by which of those three numbers $(\$ 1000, \$ 25,000$, or $\$ 125,000)$ shows up first in the question sequence. 
one and two or two and three is basically a random process and is just as likely to show a decrease as an increase.

The data in Appendixes 2, 3 and 4 show the distribution of bracket cases for those who responded DK or REF when asked about the amount of money in the various asset categories. The HRS 1998 sample was used in the analysis. Appendix 2 has counts of households in the various bracket categories, and has a complete set of tabulations for each of the ten net worth components. These include real estate properties, businesses and farms, IRAs, stocks and mutual funds, checking/savings/money market accounts, bonds, certificates of deposit and T-bills, transportation vehicles, other assets, and debts. These tabulations are organized by entry point, which varies from asset to asset and is pre-determined according to an algorithm described in Hill (1999).

Parallel to Appendix 2, Appendix 3 shows the mean values for each bracket category, along with the mean for all the cases corresponding to each entry point and the mean for all the households who responded DK or RF. A condensed version of Appendix 3 is in Appendix 4, which provides a direct, numeric foundation for Tables 2 and 3 below.

The data in Appendix 3 are based on the unweighted means for asset owners. For example, the unweighted means for those who own a real estate asset, and who responded DK when asked about the amount of their real estate asset, is \$168,006 for those with a low entry point $(\$ 2,500), \$ 205,737$ for those with a medium entry point $(\$ 125,000)$, and $\$ 238,004$ for those with a high entry point $(\$ 500,000)$. The data also show that the mean values of their real estate assets increase going from the low to middle entry point, and from the middle to the high entry point. This pattern shows up for the DK cases, for the REF cases, and for the sum of the two types of cases. 
Table 2 below details the incidence of asset increases (+) or decreases (-) for respondents in each of the possible entry points for each of the ten net worth components in the HRS study. DK responses are distinguished from REF responses. Thus, REF respondents showed an increase in Real Estate assets between entry points 1 and 2 for those who refused to give an amount of their Real Estate holdings; these respondents also showed an increase in Real Estate assets between entry points 2 and 3.

Table 2

Increases (+) and Decreases (-) in Mean Asset Values as a Function of Response Bracket Entry Points, Where 1 is the lowest of the Entry Points, 3 is the Highest

\begin{tabular}{|l|c|c|c|c|c|c|}
\hline & \multicolumn{2}{|c|}{ DK } & \multicolumn{2}{c|}{ REF } & \multicolumn{2}{c|}{ DK, REF } \\
\hline ASSET: & $1-2$ & $2-3$ & $1-2$ & $2-3$ & $\Sigma+$ & $\Sigma-$ \\
\hline Real Estate & + & + & + & + & 4 & 0 \\
\hline Business/Farm & + & + & - & + & 3 & 1 \\
\hline IRA & - & + & + & - & 2 & 2 \\
\hline Stock & + & - & - & + & 2 & 2 \\
\hline Checking/Saving & + & + & + & + & 4 & 0 \\
\hline Bonds & - & + & - & - & 1 & 3 \\
\hline CDs & + & - & - & + & 2 & 2 \\
\hline Vehicle & + & - & + & - & 2 & 2 \\
\hline Other & - & + & + & - & 2 & 2 \\
\hline Debt & + & - & - & + & 2 & 2 \\
\hline$\Sigma+$ & 7 & 6 & 5 & 6 & 24 & \\
\hline$\Sigma-$ & 3 & 4 & 5 & 4 & & 16 \\
\hline$\Sigma++$ & & 3 & & 2 & & \\
\hline$\Sigma$ Other & & 7 & & 8 & & \\
\hline
\end{tabular}

The summary statistics at the bottom of Table 2 indicate that, of the ten net worth components, increases in the means between entry points one and two or two and three (for DK respondents) can be found in seven or six cases, while decreases show up in three or four cases. For REF cases, increases show up in five of the ten categories between entry points one and two, 
and in six categories between entry points two and three. What if we ask a somewhat more demanding question—do differences in means between entry points one, two and three follow the pattern where both entry points 1-2 and 2-3 always show increases? In that test, DK cases show up as continuous increases in three of the net worth categories (Real Estate, Business/Farm, and Checking/Saving and Money Market accounts), while the other seven categories do not show continuous increases. For the REF cases, two asset categories show continuous increases (Real Estate and Checking/Saving and Money Market accounts) while eight do not. Of the sum of the DK and REF cases, five show continuous increases as entry points increase, fifteen do not. The data in Table 3 summarizes the results shown in Appendixes 2-4, and examine the consistency of the differences in mean values for the three entry points selected for each of the assets. A strong entry point bias would show up as a consistent increase in the means for each asset as we move from entry point one to entry point two, and from entry point two to entry point three. For example, owners of Real Estate show up as having entry point bias because the mean values show consistent increases from the lowest entry point to the middle point and then to the highest point. Thus the highest entry point (designated as $\mathrm{H}$ ) also shows the highest mean (designated as 3), and the lowest entry point (L) shows the lowest mean (1). But in IRAs, the lowest entry point (L) shows the highest mean (3).

Table 3 compares the rank order of means, for all net worth components and for the four types of financial assets—stocks and mutual funds, checking/savings/money market accounts, bonds, and CDs/T-bills—-for respondents who entered the bracket sequence from a DK response to the amount question, and the rank order of means for respondents who entered the bracket sequence from a REF response to the amount question. 
Table 3

\begin{tabular}{|c|c|c|c|c|c|c|}
\hline \multicolumn{7}{|c|}{$\begin{array}{l}\text { Entry Point Rank Order L, M, H (low, middle, high) } \\
\text { For Asset Owners classified as Don't Know (DK) or Refuse (REF) }\end{array}$} \\
\hline & \multicolumn{3}{|c|}{ DK } & \multicolumn{3}{|c|}{ REF } \\
\hline & \multicolumn{3}{|c|}{ Entry Point } & \multicolumn{3}{|c|}{ Entry Point } \\
\hline & $\mathrm{L}$ & $\mathrm{M}$ & $\mathrm{H}$ & $\mathrm{L}$ & $\mathrm{M}$ & $\mathrm{H}$ \\
\hline Real Estate & 1 & 2 & 3 & 1 & 2 & 3 \\
\hline Business/Farm & 1 & 2 & 3 & 2 & 1 & 3 \\
\hline IRAs & 3 & 1 & 2 & 1 & 3 & 2 \\
\hline Stock & 1 & 3 & 2 & 3 & 1 & 2 \\
\hline Chk/Sav/MM & 1 & 2 & 3 & 1 & 2 & 3 \\
\hline Bonds & 2 & 1 & 3 & 3 & 2 & 1 \\
\hline CDs, T-Bills & 1 & 3 & 2 & 2 & 1 & 3 \\
\hline Vehicles & 1 & 3 & 2 & 1 & 3 & 2 \\
\hline Other Assets & 3 & 1 & 2 & 1 & 3 & 2 \\
\hline Debts & 1 & 3 & 2 & 1 & 2 & 3 \\
\hline \multicolumn{7}{|l|}{ Entry point } \\
\hline observed & 15 & 21 & 24 & 16 & 20 & 24 \\
\hline predicted & 10 & 20 & 30 & 10 & 20 & 30 \\
\hline $\begin{array}{l}\text { Observed- } \\
\text { predicted }\end{array}$ & +5 & +1 & -6 & +6 & 0 & -6 \\
\hline \multicolumn{7}{|l|}{$\begin{array}{l}\text { Financial } \\
\text { Assets }\end{array}$} \\
\hline observed & 5 & 9 & 10 & 9 & 6 & 9 \\
\hline predicted & 4 & 8 & 12 & 4 & 8 & 12 \\
\hline $\begin{array}{l}\text { Observed- } \\
\text { predicted }\end{array}$ & +1 & +1 & -2 & +5 & -2 & -3 \\
\hline
\end{tabular}

Note: Financial assets include stocks, checking/savings/money market accounts, bonds, and CDs/T-Bills.

Overall, these tables suggest that entry point bias has some influence on the responses to these asset questions, but the influence is modest and entry point selection may not be a major source of bias. The financial asset patterns, especially those for REF cases, do not show any systematic relation between entry point and mean. While the theory calls for the highest mean to be associated with the highest entry point, and the lowest mean associated with the lowest entry 
point, the quantitative differences in the entry point patterns for REF cases are effectively zerosumming the rank order values for the lowest and highest entry points shows them to be equal.

The analysis so far has been concerned with relatively crude measures of associationcomparisons of means, the direction of change (up or down), and so forth. It seems useful to apply somewhat more rigorous statistical tests to these data, in order to determine whether any clear cut statistical signals come across from the analysis. For this purpose, we pooled together all the ten types of net worth data for those who either gave a don't know answer to the question or refused to give an answer at all. We estimated a set of simple regression models of asset level on asset type, a don’t know/refusal dummy (DK/RF), dummies for two entry point categories, and interactions between DK/RF and entry points. The results (Table 4) suggest that there were no statistically significant differences in asset level between DK and RF responses, or among different entry point categories.

Results were not drastically different when the models were estimated for each type of net worth component separately (Table 5). Of the ten individual models (nine assets and debt), entry point effects appeared only in the models for checking/savings/money market accounts and debts. In these two models, the lowest entry points were generally associated with low asset values compared to the other entry points. The DK/RF effect showed statistical significance only in the model for debts.

Is there a refinement of the entry point bias model that is more consistent with the data than the original entry point bias model? Several features of the data in Table 3 suggests a useful modification of the original model as it applies to the analysis of asset holdings. These modifications are basically driven by noting the degree of certainty associated with the response patterns. 
Table 4

\begin{tabular}{|c|c|c|}
\hline \multicolumn{3}{|c|}{$\begin{array}{c}\text { Effects of Entry Point and Missing Value Type on HRS } 1998 \text { Asset Holdings } \\
\text { In Pooled Data Models }\end{array}$} \\
\hline & Baseline Model & Full Model \\
\hline Don’t Know (DK) & 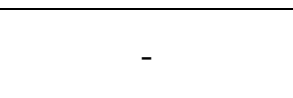 & $\begin{array}{c}-2.94 \\
(-0.35)\end{array}$ \\
\hline Low-Entry-Point (L) & - & $\begin{array}{l}-7.21 \\
(-0.81)\end{array}$ \\
\hline Middle-Entry-Point (M) & - & $\begin{array}{c}1.89 \\
(0.15)\end{array}$ \\
\hline Low-Entry-Point x DK & - & $\begin{array}{c}-4.50 \\
(-0.39)\end{array}$ \\
\hline Middle Entry-Point x RF & - & $\begin{array}{c}-7.99 \\
(-0.53) \\
\end{array}$ \\
\hline Real Estate & $\begin{array}{c}203.84 * * \\
(9.34)\end{array}$ & $\begin{array}{c}204.01^{* *} \\
(11.10)\end{array}$ \\
\hline Business/Farm & $\begin{array}{c}282.55^{* *} \\
(12.19)\end{array}$ & $\begin{array}{c}282.32^{* *} \\
(10.15)\end{array}$ \\
\hline IRAs & $\begin{array}{c}57.26^{* *} \\
(3.04)\end{array}$ & $\begin{array}{c}56.55^{* * *} \\
(11.36)\end{array}$ \\
\hline Stocks & $\begin{array}{c}157.65^{* *} \\
(8.71)\end{array}$ & $\begin{array}{c}156.94 * * \\
(6.86)\end{array}$ \\
\hline Bonds & $\begin{array}{c}75.50 * * \\
(3.07)\end{array}$ & $\begin{array}{c}75.15^{* *} \\
(7.44)\end{array}$ \\
\hline Chk/Sav/MM & $\begin{array}{l}14.43 \\
(0.86)\end{array}$ & $\begin{array}{c}13.84 * * \\
(5.65)\end{array}$ \\
\hline CDs, T-Bills & $\begin{array}{l}36.71 \\
(1.91)\end{array}$ & $\begin{array}{c}36.15^{* *} \\
(10.54) \\
\end{array}$ \\
\hline Vehicles & $\begin{array}{c}2.51 \\
(0.14)\end{array}$ & $\begin{array}{c}2.60 \\
(1.34) \\
\end{array}$ \\
\hline Other Assets & $\begin{array}{l}36.30 \\
(1.56)\end{array}$ & $\begin{array}{c}36.19 * * \\
(7.36)\end{array}$ \\
\hline Constant & $\begin{array}{l}11.80 \\
(0.76) \\
\end{array}$ & $\begin{array}{c}17.92^{* *} \\
(2.56) \\
\end{array}$ \\
\hline Adjusted $R^{2}$ & .040 & .041 \\
\hline
\end{tabular}

Note: The dependent variable was (the imputed asset value)/1000. The omitted (reference) groups were Refusal (RF), High-Entry-Point (H), and Debts. The "cluster" option was used when the models were estimated, with a cluster variable "HHID" + "FSUBHH". In the "Full Model", not all the possible interaction terms were included because of collinearity. The joint effect of entry points was statistically insignificant $(F=.71) . N=11,723$. $t$-values in parentheses. ${ }^{* *}=p<.01 . *=p<.05$. 


\section{Table 5}

\begin{tabular}{|c|c|c|c|c|c|c|c|c|}
\hline \multicolumn{9}{|c|}{$\begin{array}{c}\text { Effects of Entry Points and Missing Value Types on HRS } 1998 \text { Asset Holdings } \\
\text { In Single Asset Models }\end{array}$} \\
\hline & \multirow{2}{*}{$\begin{array}{c}\text { DK } \\
(t- \\
\text { value })\end{array}$} & \multicolumn{2}{|c|}{ Entry Point } & \multicolumn{2}{|c|}{$\begin{array}{c}\text { Entry Point and } \\
\text { DK/RF } \\
\text { Interaction } \\
\end{array}$} & \multirow{2}{*}{$\begin{array}{c}\text { Joint } \\
\text { Effect } \\
\text { of } \\
\text { Entry } \\
\text { Points } \\
\text { (F- } \\
\text { value) }\end{array}$} & \multirow{2}{*}{$\begin{array}{l}\text { Joint Effect } \\
\text { of Entry } \\
\text { Points and } \\
\text { Interactions } \\
\text { (F-value) }\end{array}$} & \multirow[b]{2}{*}{$N$} \\
\hline & & $\begin{array}{c}\mathrm{L} \\
(t \text {-value })\end{array}$ & $\begin{array}{c}\mathrm{M} \\
(t- \\
\text { value })\end{array}$ & $\begin{array}{l}\mathrm{L}^{*} \mathrm{DK} \\
(t- \\
\text { value })\end{array}$ & $\begin{array}{l}\mathrm{M} * \mathrm{RF} \\
(t- \\
\text { value })\end{array}$ & & & \\
\hline Real Estate & -1.07 & -.79 & -.74 & .21 & .20 & .58 & .72 & 571 \\
\hline Business/Farm & .32 & -.01 & -.10 & -.42 & -.29 & .01 & .33 & 454 \\
\hline IRAs & -.08 & -.51 & -.86 & .68 & 1.30 & .50 & 1.01 & 1191 \\
\hline Stocks & .03 & .16 & .78 & -.17 & -.52 & .32 & .24 & 1560 \\
\hline Bonds & .77 & 1.48 & -.98 & -1.40 & 1.22 & 1.57 & .80 & 371 \\
\hline Chk/Sav/MM & -.73 & $-2.74 * *$ & -.38 & .29 & -1.29 & $3.82 *$ & $4.77 * *$ & 3147 \\
\hline CDs, T-Bills & -.82 & -.74 & .61 & .34 & -1.74 & .46 & 1.03 & 1053 \\
\hline Vehicles & -.36 & -1.30 & -1.38 & .38 & .77 & 1.80 & $3.05 *$ & 2378 \\
\hline Other Assets & .20 & -.33 & -.17 & .25 & .50 & .07 & .18 & 444 \\
\hline Debts & $-3.24 * *$ & -2.46 & -.01 & 1.92 & -1.68 & $3.03 *$ & 1.78 & 554 \\
\hline
\end{tabular}

Note: DK = Don't Know. $\mathrm{L}=$ Low-Entry-Point. $\mathrm{M}$ = Middle-Entry-Point. The omitted (reference) groups were Refusal (RF), and High-Entry-Point (H). "Joint Effect of Entry Points" denotes an F-test that the coefficients on L and $\mathrm{M}$ are both zeros. "Joint Effect of Entry Points and Interactions" denotes an F-test that the coefficients on L, M, $\mathrm{L}^{*} \mathrm{DK}, \mathrm{M} * \mathrm{RF}$ are all zeros. ${ }^{* *}=p<.01 .{ }^{*}=p<.05$.

First, it appears to be the case that holdings of real assets are more consistent with the original entry point model than holdings of financial assets. The reason may be that the market values of real assets (the two most important being Real Estate assets and Business/Farm assets) are subject to more uncertainty than holdings of other assets. The greater uncertainty in turn might be due to the greater market volatility of these assets.

Second, it appears to be the case that REF respondents are much more random in the pattern of their mean asset holdings than DK households. That result is probably explained by the fact that REF respondents are not uncertain about the value of their asset holdings, but are 
simply unwilling to reveal them. In contrast, DK respondents, almost by definition, are very likely to be uncertain about the value of their holdings.

Next, the asset category of Checking, Saving, and Money Market accounts tends to show asset holding patterns that are consistent with the original entry point model. As noted earlier, the reason may be the uncertainty associated with the definition of "account," which may confuse many respondents who have multiple accounts and are unclear about which ones to include.

Finally, the fact that the debt category shows a significant relation to both the DK variable and the entry point variables may be due to the way in which the debt variable was measured. Each of the asset questions had a potential debt component. The specific asset question was: "If you sold all those and paid off anything you owed on them, about how much would you have?” The specific debt question was: “Aside from any debt that you have already told me about, do you have any outstanding debt?” It would not be surprising if many respondents didn't remember how they handled the asset-linked debt component, with the result that the explicit debt question might be quite unreliable. 


\section{$\underline{\text { References }}$}

Burkhauser, Richard V. and Paul J. Gertler (eds.), 1995. Special Issue of the Journal of Human Resources, “The Health and Retirement Study: Data Quality and Early Results.”

Hill, Daniel H. 1999. “Unfolding Bracket Method in the Measurement of Expenditures and Wealth.” In Robert J. Willis and James P. Smith (eds.), Wealth, Health and Work: Innovations in Measurement in the Social Sciences. Ann Arbor: University of Michigan Press.

Hurd, Michel D. 1999. “Anchoring and Acquiescence Bias in Measuring Assets in Household Surveys,” Journal of Risk and Uncertainty, 19: 111-136.

Juster, F. Thomas, and James P. Smith. 1997. "Improving the Quality of Economic Data: Lessons from the HRS and AHEAD,” Journal of the American Statistical Association, 92: 12681278.

Kahneman, Daniel.. and Amos Tversky. 1986. "Rational Choice and the Framing of Decisions," Journal of Business, 59: 251-278.

Soest, Arthur van, and Michael Hurd. 2003. "Unfolding Brackets, Anchoring and Acquiescence Bias in Panel Models for Household Asset Holdings,” Unpublished manuscript, Rand.

Tversky, Amos, and Daniel Kahneman. 1974. “Judgment Under Uncertainty: Heuristics and Bias,” Science, 185: 1124-1131

Tversky, Amos, and Daniel Kahneman. 1981. "The Framing of Decisions and the Psychology of Choice,” Science, 211: 453-458 


\section{Appendix 1. Structure of Unfolding Bracket Question Sequence}

Unfolding brackets as a survey technique aiming to reduce item non-responses have been used widely in HRS in questions related to income, assets, and health care expenditures. A complete unfolding bracket question sequence generally consists of three sets of questions: ownership, amount or open-ended question, and bracket questions, as illustrated in the following example for stocks/mutual funds holdings (Table A1).

Table A1. Unfolding Bracket Question Sequence for Stocks/Mutual Funds Holdings

\section{Panel 1. For Low Entry Point Group}

(Ownership Question)

A). (Aside from anything you have already told me about,) Do you (or your [husband/wife/partner]) have any shares of stock or stock mutual funds?

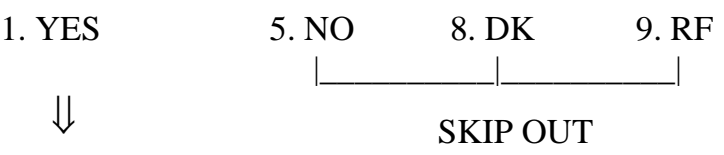

(Amount or Open-Ended Question)

B. If you sold all those and paid off anything you owed on them, about how much would you have?

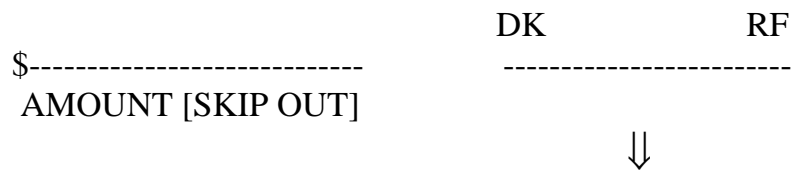

(Bracket Questions)

C1. Would it amount to less than $\$ 2,500$, more than $\$ 2,500$, or what?
1. Less than $\$ 2,500$ [SKIP OUT]
5. More than $\$ 2,500$ [Go to C2]
3. About $\$ 2,500$ [SKIP OUT]
8. DK
9. RF

SKIP OUT

C2. Would it amount to less than $\$ 25,000$, more than $\$ 25,000$, or what?
1. Less than $\$ 25,000$ [SKIP OUT]
5. More than $\$ 25,000$ [Go to C3]
3. About $\$ 25,000$ [SKIP OUT]
8. DK
9. RF

C3. Would it amount to less than $\$ 125,000$, more than $\$ 125,000$, or what?

1. Less than $\$ 125,000$ [SKIP OUT]

5. More than $\$ 125,000$ [Go to C4]

3. About $\$ 125,000$ [SKIP OUT]

8. DK 9. RF

SKIP OUT__ 
C4. Would it amount to less than $\$ 400,000$, more than $\$ 400,000$, or what?

1. Less than $\$ 400,000$ [SKIP OUT]

3. About $\$ 400,000$ [SKIP OUT]

5. More than $\$ 400,000$ [SKIP OUT]

8. DK

9. RF

\section{Panel 2. For Middle Entry Point Group}

(Ownership Question)

A). (Aside from anything you have already told me about,) Do you (or your [husband/wife/partner]) have any shares of stock or stock mutual funds?

1. YES

$\Downarrow$
5. NO 8. DK 9. RF

SKIP OUT

(Amount or Open-Ended Question)

B. If you sold all those and paid off anything you owed on them, about how much would you have?

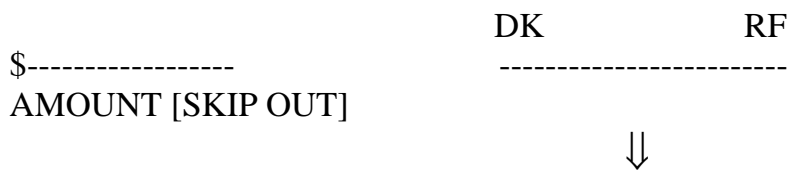

(Bracket Questions)

C2. Would it amount to less than $\$ 25,000$, more than $\$ 25,000$, or what?
1. Less than $\$ 25,000$ [Go to C1]
3. About $\$ 25,000$ [SKIP OUT]
5. More than $\$ 25,000$ [Go to C3]
8. DK
9. RF

C1. Would it amount to less than $\$ 2,500$, more than $\$ 2,500$, or what?
1. Less than $\$ 2,500$ [SKIP OUT]
3. About $\$ 2,500$ [SKIP OUT]
5. More than $\$ 2,500$ [SKIP OUT]
8. DK
9. $\mathrm{RF}$
___ SKIP OUT_

C3. Would it amount to less than $\$ 125,000$, more than $\$ 125,000$, or what?
1. Less than $\$ 125,000$ [SKIP OUT]
5. More than $\$ 125,000$ [Go to C4]
3. About $\$ 125,000$ [SKIP OUT]
8. DK 9. RF
SKIP OUT__

C4. Would it amount to less than $\$ 400,000$, more than $\$ 400,000$, or what?

1. Less than $\$ 400,000$ [SKIP OUT]

5. More than $\$ 400,000$ [SKIP OUT]
3. About $\$ 400,000$ [SKIP OUT]
8. DK
9. RF 


\section{Panel 3. For High Entry Point Group}

(Ownership Question)

A). (Aside from anything you have already told me about,) Do you (or your [husband/wife/partner]) have any shares of stock or stock mutual funds?

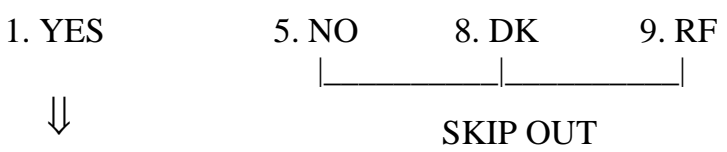

(Amount or Open-Ended Question)

B. If you sold all those and paid off anything you owed on them, about how much would you have?

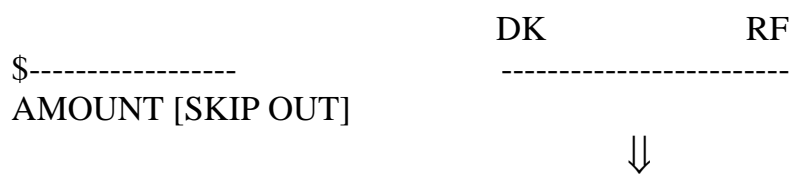

(Bracket Questions)

C3. Would it amount to less than $\$ 125,000$, more than $\$ 125,000$, or what?
1. Less than $\$ 125,000$ [Go to C2]
3. About $\$ 125,000$ [SKIP OUT]
5. More than $\$ 125,000$ [Go to C4]
8. DK
9. RF

C2. Would it amount to less than $\$ 25,000$, more than $\$ 25,000$, or what?
1. Less than $\$ 25,000$ [Go to C1]
3. About $\$ 25,000$ [SKIP OUT]
5. More than $\$ 25,000$ [SKIP OUT]
8. DK
9. RF

C1. Would it amount to less than $\$ 2,500$, more than $\$ 2,500$, or what?
1. Less than $\$ 2,500$ [SKIP OUT]
3. About $\$ 2,500$ [SKIP OUT]
5. More than $\$ 2,500$ [SKIP OUT]
8. DK
9. RF

C4. Would it amount to less than $\$ 400,000$, more than $\$ 400,000$, or what?

1. Less than $\$ 400,000$ [SKIP OUT]
5. More than $\$ 400,000$ [SKIP OUT]

3. About $\$ 400,000$ [SKIP OUT]

8. DK 9. RF

SKIP OUT

What distinguishes an unfolding bracket sequence from traditional survey questions is its inclusion of range questions (less than $x$, about $x$, more than $x$ ), which become necessary for those who give a positive answer to the ownership question but fail to provide a specific amount to the open-ended question. 
An unfolding bracket sequence can be characterized by the number of breakpoints and the values of these breakpoints, which in HRS are pre-determined based on an algorithm described in Hill (1999). In the above example, the unfolding bracket sequence has four breakpoints, valued at $\$ 2,500, \$ 25,000, \$ 125,000$, and $\$ 400,000$, respectively. Different bracket sequences may have a different number of breakpoints, and/or different breakpoint values. The bracket sequence for transportation vehicles in HRS 1998, for example, has only three breakpoints, with breakpoint values at $\$ 5,000, \$ 50,000$, and $\$ 100,000$.

Another feature of an HRS unfolding bracket sequence is that the sequence stops whenever a DK or RF answer is given to a bracket question. Thus, many stock-owning households do not provide any definitive information at all regarding the value of their stock holdings even when prompted with bracket questions. ${ }^{5}$ The sequence also stops when bracket questions are at an upper or lower limit (e.g., less than the lowest breakpoint, or more than the highest breakpoint), when an "about" answer is given, or when a lower and upper bracket limit is identified.

Entry points become an issue in the unfolding bracket sequence because the distribution of respondents among bracket categories may depend on the entry bracket. Prior to interview and since HRS 1998, each HRS household is assigned to one of three randomly selected groups, which may conveniently be called a low-entry-point group, a middle-entry-point group, and a high-entry-point group, respectively.

Households assigned to the low-entry-point group will get bracket questions starting with lowest breakpoint—in this case, $\$ 2,500$. They will first be asked question C1, then C2, and C3, and conclude the bracket sequence with C4 if needed (See Table A1, Panel 1). In contrast, households assigned to the middle-entry-point group will get bracket questions starting with the

\footnotetext{
${ }^{5}$ That is, they give a DK/RF answer to the entry bracket question, and the bracket sequence stops right there.
} 
second lowest breakpoint - in this case, \$25,000. They will first be asked question C2, and then-depending on their answers to the question—C1, or C3 and C4 (See Table A1, Panel 2). The bracket question sequence for households assigned to the high-entry-point group is determined in a similar way: starting with $\mathrm{C} 3$, and then $\mathrm{C} 4$, or $\mathrm{C} 2$ and $\mathrm{C} 1$ - depending on their answers to a previous question (See Table A1, Panel 3).

"Unfolding range" is a term used for characterizing respondent answers to the entire sequence of bracket questions. In combination with entry-point, unfolding range uniquely determines a respondent's response pattern to various bracket questions. For a stock-owning household who belongs to the low-entry-point group and who fails to reveal the exact value of its stock holdings, for example, its answers to the bracket questions may be as follows: $\mathrm{C} 1=5, \mathrm{C} 2=$ 5 , and C3 $=1$. We know that this household's holdings are greater than $\$ 25,000$ and less than $\$ 125,000$, and denote its unfolding range as “ $>\$ 25,000$ and $<\$ 125,000$.” Similarly, the unfolding range for a household in the high-entry-point group with bracket answers C3 = 1, $\mathrm{C} 2=1$, and $\mathrm{C} 1=5$ is " $>\$ 2,500$ and $<\$ 25,000$."

Table A2 lists all the possible unfolding ranges for stock-owning households in the four breakpoint unfolding sequence illustrated above. Readers may find it useful for understanding the data in Appendixes 2 and 3 of this paper.

\section{Appendices 2 and 3: A Summary}

Appendix 2 provides the details of the imputation results for each of the 10 net worth components in the HRS study (nine assets and debt). The top half of the table shows the raw counts of numbers of household respondents by unfolding bracket range, while the bottom half of the table shows the distribution of household respondents by unfolding bracket categories. 
Table A2. Possible Unfolding Ranges for Stocks/Mutual Funds Holdings

\begin{tabular}{|c|c|c|c|}
\hline Bracket Pattern & Entry-Point Group & $\begin{array}{c}\text { Why Bracket } \\
\text { Sequence Stops }\end{array}$ & Unfolding Range \\
\hline$C 1=1$ & Low-entry-point & 1 & $<\$ 2,500$ \\
\hline$C 1=3$ & Low-entry-point & 2 & About $\$ 2,500$ \\
\hline $\mathrm{C} 1=8$ or 9 & Low-entry-point & 3 & $\mathrm{DK} / \mathrm{RF}$ if $<>\$ 2,500$ \\
\hline$C 1=5, C 2=1$ & Low-entry-point & 4 & $>\$ 2,500 \&<\$ 25,000$ \\
\hline $\mathrm{C} 1=5, \mathrm{C} 2=3$ & Low-entry-point & 2 & About $\$ 25,000$ \\
\hline$C 1=5, C 2=8$ or 9 & Low-entry-point & 3 & $D K / R F$ if $<>\$ 25,000$ \\
\hline$C 1=5, C 2=5, C 3=1$ & Low-entry-point & 4 & $>\$ 25,000 \&<\$ 125,000$ \\
\hline$C 1=5, C 2=5, C 3=3$ & Low-entry-point & 2 & About $\$ 125,000$ \\
\hline$C 1=5, C 2=5, C 3=8$ or 9 & Low-entry-point & 3 & DK/RF if $<>\$ 125,000$ \\
\hline$C 1=5, C 2=5, C 3=5, C 4=1$ & Low-entry-point & 4 & $>\$ 125,000 \&<\$ 400,000$ \\
\hline$C 1=5, C 2=5, C 3=5, C 4=3$ & Low-entry-point & 2 & About $\$ 400,000$ \\
\hline$C 1=5, C 2=5, C 3=5, C 4=8$ or 9 & Low-entry-point & 3 & DK/RF if $<>\$ 400,000$ \\
\hline$C 1=5, C 2=5, C 3=5, C 5=5$ & Low-entry-point & 1 & $>\$ 400,000$ \\
\hline$C 2=1, C 1=1$ & Middle-entry-point & 1 & $<\$ 2,500$ \\
\hline $\mathrm{C} 2=1, \mathrm{C} 1=3$ & Middle-entry-point & 2 & About $\$ 2,500$ \\
\hline$C 2=1, C 1=8$ or 9 & Middle-entry-point & 3 & $D K / R F$ if $<>\$ 2,500$ \\
\hline $\mathrm{C} 2=1, \mathrm{C} 1=5$ & Middle-entry-point & 4 & $>\$ 2,500 \&<\$ 25,000$ \\
\hline $\mathrm{C} 2=3$ & Middle-entry-point & 2 & About $\$ 25,000$ \\
\hline $\mathrm{C} 2=8$ or 9 & Middle-entry-point & 3 & DK/RF if $<>\$ 25,000$ \\
\hline $\mathrm{C} 2=5, \mathrm{C} 3=1$ & Middle-entry-point & 4 & $>\$ 25,000 \&<\$ 125,000$ \\
\hline $\mathrm{C} 2=5, \mathrm{C} 3=3$ & Middle-entry-point & 2 & About $\$ 125,000$ \\
\hline $\mathrm{C} 2=5, \mathrm{C} 3=8$ or 9 & Middle-entry-point & 3 & DK/RF if $<>\$ 125,000$ \\
\hline $\mathrm{C} 2=5, \mathrm{C} 3=5, \mathrm{C} 4=1$ & Middle-entry-point & 4 & $>\$ 125,000 \&<\$ 400,000$ \\
\hline $\mathrm{C} 2=5, \mathrm{C} 3=5, \mathrm{C} 4=3$ & Middle-entry-point & 2 & About $\$ 400,000$ \\
\hline $\mathrm{C} 2=5, \mathrm{C} 3=5, \mathrm{C} 4=8$ or 9 & Middle-entry-point & 3 & DK/RF if $<>\$ 400,000$ \\
\hline $\mathrm{C} 2=5, \mathrm{C} 3=5, \mathrm{C} 4=5$ & Middle-entry-point & 1 & $>\$ 400,000$ \\
\hline$C 3=1, C 2=1, C 1=1$ & High-entry-point & 1 & $<\$ 2,500$ \\
\hline$C 3=1, C 2=1, C 1=3$ & High-entry-point & 2 & About $\$ 2,500$ \\
\hline$C 3=1, C 2=1, C 1=8$ or 9 & High-entry-point & 3 & $\mathrm{DK} / \mathrm{RF}$ if $<>\$ 2,500$ \\
\hline $\mathrm{C} 3=1, \mathrm{C} 2=1, \mathrm{C} 1=5$ & High-entry-point & 4 & $>\$ 2,500 \&<\$ 25,000$ \\
\hline $\mathrm{C} 3=1, \mathrm{C} 2=3$ & High-entry-point & 2 & About $\$ 25,000$ \\
\hline $\mathrm{C} 3=1, \mathrm{C} 2=8$ or 9 & High-entry-point & 3 & $D K / R F$ if $<>\$ 25,000$ \\
\hline $\mathrm{C} 3=1, \mathrm{C} 2=5$ & High-entry-point & 4 & $>\$ 25,000 \&<\$ 125,000$ \\
\hline $\mathrm{C} 3=3$ & High-entry-point & 2 & About $\$ 125,000$ \\
\hline $\mathrm{C} 3=8$ or 9 & High-entry-point & 3 & $D K / R F$ if $<>\$ 125,000$ \\
\hline$C 3=5, C 4=1$ & High-entry-point & 4 & $>\$ 125,000 \&<\$ 400,000$ \\
\hline $\mathrm{C} 3=5, \mathrm{C} 4=3$ & High-entry-point & 2 & About $\$ 400,000$ \\
\hline$C 3=5, C 4=8$ or 9 & High-entry-point & 3 & DK/RF if $<>\$ 400,000$ \\
\hline $\mathrm{C} 3=5, \mathrm{C} 4=5$ & High-entry-point & 1 & $>\$ 400,000$ \\
\hline
\end{tabular}

Note: 1) The unfolding sequence has four breakpoints valued at \$2,500, \$25,000, \$125,000, and \$400,000. 2)Bracket pattern is arranged in the order of bracket questions answered. 2) Households from the low-entry-point group always start with question C1. Households from the middle-entry-point group always start with question C2. Households from the high-entry-point group always start with question C3. 3) Reason why bracket sequence stops: $1=$ bracket question is at an upper or lower limit; 2 = an "about" answer is given; $3=$ a "DK" or "RF" answer is given; $4=$ a lower and upper bracket limit is identified (e.g., the amount is less than $\$ 50,000$ and greater than $\$ 5000$ ). 
The table is divided into 10 panels (one panel for each net worth component); three major components for each panel (respondents who reported don’t know (DK) when asked asset amount, those who reported refuse (RF) when asked about asset amount, and the sum of the don't know and refuse respondents); and three randomly selected entry points which vary by type of asset. Thus, for example, Panel 1 deals with Real Estate holdings, shows the numbers of households who replied don't know or refused for each of the three entry points $(2.5 \mathrm{~K}, 125 \mathrm{~K}$, and $500 \mathrm{~K}$ ) and for each of the 13 unfolding bracket ranges. The bottom half of the table shows the percent distribution of households in each of six bracket categories.

The largest and most consistent difference in the data shown in Appendix 2 is in the distributions of DK cases and RF cases. For DK cases, only about ten percent of households could not provide a bracket amount when asked the entry bracket question, and another roughly 8-9 percent could not provide a response when asked the bracket question somewhere other than in the entry bracket sequence. (These numbers are taken from Panel 1 of Appendix 2, which asks about Real Estate assets.) In contrast, fully sixty percent of households refused to provide a bracket response when asked the entry bracket question, and another roughly 15\% would not provide a bracket response when asked the bracket question somewhere other than in the entry bracket sequence. Comparable numbers are found for other assets, with the general pattern being that the refusal rate for the entry bracket questions is even higher—more like $70 \%$ than sixty.

Appendix 3 contains mean amounts for each of the bracket categories, with the amount being obtained by random draws for each household in each of the bracket categories. That is, if 50 households wound up in the bracket category “ $<\$ 50 \mathrm{~K}>\$ 5 \mathrm{~K}$ ”, the program would search the data for continuous amount cases in that category, then assign a randomly selected case for each of the 50 households. In cases where the respondent said that their asset was worth "about $10 \mathrm{~K}$ ", 
when asked whether it was worth “< $\$ 10 \mathrm{~K},>$ \$10K, or what?”, the program would assign $\$ 10 \mathrm{~K}$ to each of the households in the "about $\$ 10 \mathrm{~K}$ " category. 


\section{Appendix 2}

Distribution of HRS 1998 sample by unfolding bracket Range, Entry Point, and whether DK or REF

in Response to questions about Asset holdings (unweighted N)

HRS 1998: Value of Real Estate Holdings

\section{Panel 1: Real Estate Holdings}

\section{DK to open-ended question}

Random entry point:

Unfolding range

$<\$ 2,500$

About $\$ 2,500$

$\mathrm{DK} / \mathrm{RF}$ if $<>\$ 2,500$

$>\$ 2,500 \&<\$ 125,000$

About $\$ 125,000$

$\mathrm{DK} / \mathrm{RF}$ if $<>\$ 125,000$

$>\$ 125,000 \&<\$ 500,000$

About $\$ 500,000$

$\mathrm{DK} / \mathrm{RF}$ if $<>\$ 500,000$

$>\$ 500,000 \&<\$ 1,000,000$

About $\$ 1,000,000$

$\mathrm{DK} / \mathrm{RF}$ if $<>\$ 1,000,000$

$>\$ 1,000,000$

Total Case Number

\section{$\$ 2,500 \$ 125,000 \quad \$ 500,000$}

$\begin{array}{rrr}9 & 7 & 9 \\ 10 & 3 & 2 \\ 16 & 5 & 7 \\ 74 & 67 & 59 \\ 13 & 6 & 5 \\ 9 & 24 & 6 \\ 29 & 16 & 33 \\ 1 & 6 & 2 \\ 4 & 3 & 17 \\ 8 & 11 & 8 \\ 3 & 2 & 4 \\ 0 & 2 & 1 \\ 2 & 4 & 4 \\ 178 & 156 & 157\end{array}$

Percentage Distribution by Bracket Category

DK/RF to entry-bracket question

DK/RF to non-entry-bracket question $\quad 7.3 \%$

$<\$ 2,500$

$>=\$ 2,500 \&<\$ 125,000$

$>=\$ 125,000 \&<\$ 500,000$

$>=\$ 500,000$

Total

$9.0 \%$
$7.3 \%$
$5.1 \%$
$47.2 \%$
$23.6 \%$
$7.9 \%$
$100.0 \%$

Refusal to open-ended question

\author{
Random entry point: \\ $\$ 2,500 \quad \$ 125,000 \quad \$ 500,000$
}

Random entry point: $\$ 2,500 \quad \$ 125,000 \quad \$ 500,000$

9

2

59

5

6

33

2

17

8

4

1

$\begin{array}{rrr}1 & 0 & 1 \\ 12 & 0 & 2 \\ 3 & 1 & 3 \\ 2 & 0 & 1 \\ 3 & 23 & 3 \\ 0 & 2 & 0 \\ 1 & 2 & 14 \\ 0 & 1 & 1 \\ 0 & 2 & 0 \\ 1 & 0 & 1 \\ 23 & 31 & 26\end{array}$

$\begin{array}{rrrr}52.2 \% & 74.2 \% & 53.8 \% & 61 \\ 17.4 \% & 12.9 \% & 19.2 \% & \\ 4.3 \% & 0.0 \% & 3.8 \% & \\ 13.0 \% & 3.2 \% & 11.5 \% & \\ 8.7 \% & 6.5 \% & 3.8 \% \\ 4.3 \% & 3.2 \% & 7.7 \% \\ 100.0 \% & 100.0 \% & 100.0 \%\end{array}$

$61.3 \%$

$13.9 \%$
$8.5 \%$
$5.0 \%$
$43.3 \%$
$21.9 \%$
$7.5 \%$
$100.0 \%$

$\begin{array}{rr}25.1 \% & 16.9 \% \\ 7.5 \% & 10.4 \% \\ 3.7 \% & 5.5 \% \\ 38.0 \% & 35.0 \% \\ 12.8 \% & 21.3 \% \\ 12.8 \% & 10.9 \% \\ 100.0 \% & 100.0 \%\end{array}$

Note: 1) Entry bracket categories are highlighted. 2) "DK/RF to entry-bracket question" is calculated as ratio of the highlighted cell to the total case number. 3) "DK/RF to non-entry-bracket question" is calculated as ratio of all the non-highlighted cells ending in DK/RF to the total case number. 


\section{Panel 2: Business/Farm Asset Holdings}

HRS 1998: Business/Farm Asset Holding

DK to open-ended question

Random entry point:

Unfolding range

$<\$ 5,000$

$\mathrm{DK} / \mathrm{RF}$ if $<>\$ 5,000$

$>\$ 5,000 \&<\$ 10,000$

About $\$ 10,000$

$>\$ 10,000 \&<\$ 100,000$

About $\$ 100,000$

$\mathrm{DK} / \mathrm{RF}$ if $<>\$ 100,000$

$>\$ 100,000 \&<\$ 1,000,000$

$\mathrm{DK} / \mathrm{RF}$ if $<>\$ 1,000,000$

$>\$ 1,000,000$

Total Case Number
$\mathrm{DK} / \mathrm{RF}$ if $<>\$ 10,000$

About $\$ 1,000,000$
About $\$ 5,000$

\section{$\$ 5,000 \quad \$ 10,000 \quad \$ 100,000$}

Percentage Distribution by Bracket Category

DK/RF to entry-bracket question

$\mathrm{DK} / \mathrm{RF}$ to non-entry-bracket question

$<\$ 5,000$

$>=\$ 5,000 \&<\$ 10,000$

$>=\$ 10,000 \&<\$ 100,000$

$>=\$ 100,000$

Total

$\begin{array}{rrr}13 & 6 & 6 \\ 4 & 2 & 3 \\ 25 & 0 & 0 \\ 3 & 5 & 2 \\ 4 & 5 & 4 \\ 3 & 22 & 1 \\ 30 & 25 & 28 \\ 9 & 9 & 2 \\ 5 & 7 & 30 \\ 22 & 39 & 33 \\ 1 & 3 & 3 \\ 1 & 1 & 0 \\ 3 & 3 & 10 \\ & & \\ 123 & 127 & 122\end{array}$

$20.3 \%$

$7.3 \%$

$10.6 \%$

$5.7 \%$

$27.6 \%$

$28.5 \%$

$100.0 \%$
Refusal to open-ended question

Random entry point: $\$ 5,000 \quad \$ 10,000 \quad \$ 100,000$

0

30

3

0
10

22

\section{$17.3 \% \quad 24.6 \%$}

$\begin{array}{rr}6.3 \% & 0.8 \% \\ 4.7 \% & 4.9 \%\end{array}$

$\begin{array}{rr}4.7 \% & 4.9 \% \\ 5.5 \% & 4.1 \% \\ 23.6 \% & 26.2 \%\end{array}$

20.7\%

$\begin{array}{rrr}63.6 \% & 60.9 \% & 84.6 \% \\ 15.2 \% & 13.0 \% & 3.8 \% \\ 0.0 \% & 0.0 \% & 0.0 \% \\ 3.0 \% & 0.0 \% & 0.0 \% \\ 12.1 \% & 8.7 \% & 7.7 \% \\ 6.1 \% & 17.4 \% & 3.8 \% \\ 100.0 \% & 100.0 \% & 100.0 \%\end{array}$

Random entry point: $\$ 5,000 \quad \$ 10,000 \quad \$ 100,000$

$\begin{array}{rrr}13 & 6 & 6 \\ 5 & 2 & 3 \\ 46 & 0 & 0 \\ 3 & 5 & 2 \\ 5 & 5 & 4 \\ 4 & 36 & 1 \\ 33 & 27 & 30 \\ 9 & 10 & 2 \\ 8 & 8 & 52 \\ 24 & 42 & 33 \\ 1 & 3 & 3 \\ 2 & 3 & 1 \\ 3 & 3 & 11 \\ 156 & 150 & 148\end{array}$

Note: 1) Entry bracket categories are highlighted. 2) "DK/RF to entry-bracket question" is calculated as ratio of the highlighted cell to the total case number. 3) "DK/RF to non-entry-bracket question" is calculated as ratio of all the non-highlighted cells ending in DK/RF to the total case number. 


\section{Panel 3: IRA - 1 Holdings}

HRS 1998: IRA - 1 Holdings

\section{DK to open-ended question}

Random entry point:

Unfolding range

$<\$ 10,000$

About $\$ 10,000$

DK/RF if $<>\$ 10,000$

$>\$ 10,000 \&<\$ 25,000$

About $\$ 25,000$

$\mathrm{DK} / \mathrm{RF}$ if $<>\$ 25,000$

$>\$ 25,000 \&<\$ 100,000$

About \$100,000

DK/RF if $<>\$ 100,000$

$>\$ 100,000 \&<\$ 400,000$

About $\$ 400,000$

DK/RF if $<>\$ 400,000$

$>\$ 400,000$

Total Case Number

\begin{abstract}
$\$ 10,000 \$ 25,000 \$ 100,000$
\end{abstract}

$\begin{array}{rrr}48 & 40 & 29 \\ 15 & 13 & 7 \\ 41 & 4 & 2 \\ 36 & 44 & 22 \\ 12 & 13 & 23 \\ 9 & 45 & 13 \\ 42 & 68 & 62 \\ 3 & 8 & 4 \\ 6 & 4 & 53 \\ 21 & 19 & 21 \\ 2 & 0 & 2 \\ 1 & 2 & 2 \\ 6 & 6 & 2 \\ & & \end{array}$

Percentage Distribution by Bracket Category

DK/RF to entry-bracket question

DK/RF to non-entry-bracket question

$<\$ 10,000$

$>=\$ 10,000 \&<\$ 25,000$

$>=\$ 25,000 \&<\$ 100,000$

$>=\$ 100,000$

Total

$\begin{array}{rrr}16.9 \% & 16.9 \% & 21.9 \% \\ 6.6 \% & 3.8 \% & 7.0 \% \\ 19.8 \% & 15.0 \% & 12.0 \% \\ 21.1 \% & 21.4 \% & 12.0 \% \\ 22.3 \% & 30.5 \% & 35.1 \% \\ 13.2 \% & 12.4 \% & 12.0 \% \\ 100.0 \% & 100.0 \% & 100.0 \%\end{array}$

Refusal to open-ended question

Random entry point: $\$ 10,000 \$ 25,000 \$ 100,000$

Random entry point: $\$ 10,000 \quad \$ 25,000 \quad \$ 100,000$

$\begin{array}{rrr}12 & 6 & \\ 2 & 0 & \\ 85 & 3 & \\ 4 & 6 & \\ 1 & 3 & \\ 10 & 97 & 13 \\ 12 & 17 & 23 \\ 7 & 4 & 85 \\ 5 & 5 & \\ 0 & 1 & \\ 1 & 3 & \\ 2 & 0 & \\ 141 & 145 & \end{array}$

$\begin{array}{rrr}60 & 46 & 34 \\ 17 & 13 & 10 \\ 126 & 7 & 4 \\ 40 & 50 & 30 \\ 13 & 16 & 26 \\ 19 & 142 & 26 \\ 54 & 85 & 85 \\ 3 & 8 & 4 \\ 13 & 8 & 138 \\ 26 & 24 & 29 \\ 2 & 1 & 2 \\ 2 & 5 & 4 \\ 8 & 6 & 5 \\ 383 & 411 & 397\end{array}$

$18.5 \%$

\section{5}

8

3

13

23

85

8

0

2

155

\begin{tabular}{|c|c|c|c|c|c|c|}
\hline $60.3 \%$ & $66.9 \%$ & $54.8 \%$ & $60.5 \%$ & $32.9 \%$ & $34.5 \%$ & $34.8 \%$ \\
\hline $12.8 \%$ & $6.9 \%$ & $11.0 \%$ & & $8.9 \%$ & $4.9 \%$ & $8.6 \%$ \\
\hline $8.5 \%$ & $4.1 \%$ & $3.2 \%$ & & $15.7 \%$ & $11.2 \%$ & $8.6 \%$ \\
\hline $4.3 \%$ & $4.1 \%$ & $7.1 \%$ & & $14.9 \%$ & $15.3 \%$ & $10.1 \%$ \\
\hline $9.2 \%$ & $13.8 \%$ & $16.8 \%$ & & $17.5 \%$ & $24.6 \%$ & $28.0 \%$ \\
\hline $5.0 \%$ & $4.1 \%$ & $7.1 \%$ & & $10.2 \%$ & $9.5 \%$ & $10.1 \%$ \\
\hline $100.0 \%$ & $100.0 \%$ & $100.0 \%$ & & $100.0 \%$ & $100.0 \%$ & $100.0 \%$ \\
\hline
\end{tabular}

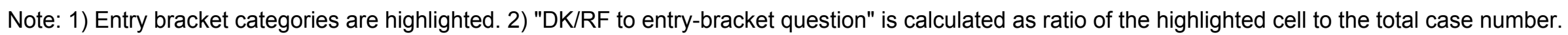
3 ) "DK/RF to non-entry-bracket question" is calculated as ratio of all the non-highlighted cells ending in DK/RF to the total case number. 
Panel 4: Stock Holdings

HRS 1998: Value of Stock Holdings

DK to open-ended question

Random entry point:

Unfolding range

$<\$ 2,500$

About $\$ 2,500$

$\mathrm{DK} / \mathrm{RF}$ if $<>\$ 2,500$

$>\$ 2,500 \&<\$ 25,000$

About $\$ 25,000$

$\mathrm{DK} / \mathrm{RF}$ if $<>\$ 25,000$

$>\$ 25,000 \&<\$ 125,000$

About $\$ 125,000$

DK/RF if $<>\$ 125,000$

$>\$ 125,000 \&<\$ 400,000$

About $\$ 400,000$

$\mathrm{DK} / \mathrm{RF}$ if $<>\$ 400,000$

$>\$ 400,000$

Total Case Number

\begin{abstract}
$\$ 2,500 \quad \$ 25,000 \quad \$ 125,000$
\end{abstract}

$\begin{array}{rrr}46 & 25 & 37 \\ 12 & 11 & 9 \\ \mathbf{5 8} & 11 & 2 \\ 71 & 91 & 68 \\ 18 & 19 & 16 \\ 12 & \mathbf{6 8} & 26 \\ 61 & 71 & 96 \\ 11 & 12 & 13 \\ 10 & 12 & \mathbf{7 8} \\ 27 & 49 & 48 \\ 0 & 4 & 8 \\ 7 & 2 & 5 \\ 17 & 26 & 24 \\ & & \\ 350 & 401 & 430\end{array}$

Percentage Distribution by Bracket Category

DK/RF to entry-bracket question $\quad 16.6 \%$

DK/RF to non-entry-bracket question

$<\$ 2,500$

$>=\$ 2,500 \&<\$ 25,000$

$>=\$ 25,000 \&<\$ 125,000$

$>=\$ 125,000$

Total

$\begin{array}{rrr}16.6 \% & 17.0 \% & 18.1 \% \\ 8.3 \% & 6.2 \% & 7.7 \% \\ 13.1 \% & 6.2 \% & 8.6 \% \\ 23.7 \% & 25.4 \% & 17.9 \% \\ 22.6 \% & 22.4 \% & 26.0 \% \\ 15.7 \% & 22.7 \% & 21.6 \% \\ 100.0 \% & 100.0 \% & 100.0 \%\end{array}$

Refusal to open-ended question

Random entry point: $\$ 2,500 \quad \$ 25,000 \quad \$ 125,000$

Random entry point: $\$ 2,500 \quad \$ 25,000 \quad \$ 125,000$

$\begin{array}{rr}2 \\ 69 \\ 7 & 10 \\ 1 & \\ 11 & 8 \\ 7 & 14 \\ 2 & \\ 3 & \\ 1 & \\ 0 & \\ 0 & \\ 3 & \\ 106 & \end{array}$

\begin{tabular}{rr}
0 & 0 \\
2 & 0 \\
0 & 6 \\
4 & 1 \\
8 & 2 \\
4 & 9 \\
0 & 5 \\
9 & 86 \\
5 & 10 \\
2 & 0 \\
2 & 7 \\
6 & 5 \\
& \\
2 & 131 \\
& \\
& \\
\hline & \\
\hline & $65.6 \%$ \\
\hline & $6.9 \%$ \\
\hline & $0.0 \%$ \\
\hline & $4.6 \%$ \\
\hline & $7.6 \%$ \\
\hline $15.3 \%$ \\
\hline $0.0 \%$
\end{tabular}

$\begin{array}{rrr}48 & 25 & 37 \\ 12 & 11 & 9 \\ 127 & 13 & 2 \\ 78 & 101 & 74 \\ 19 & 23 & 17 \\ 23 & 156 & 28 \\ 68 & 85 & 105 \\ 13 & 12 & 18 \\ 13 & 21 & 164 \\ 28 & 54 & 58 \\ 0 & 6 & 8 \\ 7 & 4 & 12 \\ 20 & 32 & 29 \\ & & \\ 456 & 543 & 561\end{array}$

$\begin{array}{rrr}65.1 \% & 62.0 \% & 65.6 \% \\ 13.2 \% & 9.2 \% & 6.9 \% \\ 1.9 \% & 0.0 \% & 0.0 \% \\ 6.6 \% & 7.0 \% & 4.6 \% \\ 7.5 \% & 12.7 \% & 7.6 \% \\ 5.7 \% & 9.2 \% & 15.3 \% \\ 100.0 \% & 100.0 \% & 100.0 \%\end{array}$

$\begin{array}{rrr}64.1 \% & 27.9 \% & 28.7 \% \\ 9.4 \% & 7.0 \% \\ 10.5 \% & 4.6 \% \\ 19.7 \% & 20.6 \% \\ 19.1 \% & 19.9 \% \\ 13.4 \% & 19.2 \% \\ 100.0 \% & 100.0 \%\end{array}$

$29.2 \%$ $7.5 \%$

$6.6 \%$

$14.8 \%$

$21.7 \%$

$20.1 \%$

$100.0 \%$

Note: 1) Entry bracket categories are highlighted. 2) "DK/RF to entry-bracket question" is calculated as ratio of the highlighted cell to the total case number.

3) "DK/RF to non-entry-bracket question" is calculated as ratio of all the non-highlighted cells ending in DK/RF to the total case number. 
HRS 1998: Value of Checking and Savings Accounts Holdings

DK to open-ended question

Random entry point:

Unfolding range

$<\$ 5,000$

About $\$ 5,000$

$\mathrm{DK} / \mathrm{RF}$ if $<>\$ 5,000$

$>\$ 5,000 \&<\$ 50,000$

About $\$ 50,000$

DK/RF if $<>\$ 50,000$

$>\$ 50,000 \&<\$ 150,000$

About $\$ 150,000$

$\mathrm{DK} / \mathrm{RF}$ if $<>\$ 150,000$

$>\$ 150,000 \&<\$ 300,000$

About $\$ 300,000$

$\mathrm{DK} / \mathrm{RF}$ if $<>\$ 300,000$

$>\$ 300,000$

Total Case Number

Percentage Distribution by Bracket Category

DK/RF to entry-bracket question $\quad 14.4 \%$

DK/RF to non-entry-bracket question

$<\$ 5,000$

$>=\$ 5,000 \&<\$ 50,000$

$>=\$ 50,000 \&<\$ 150,000$

$>=\$ 150,000$

Total

\begin{abstract}
$\$ 5,000 \quad \$ 50,000 \quad \$ 150,000$
\end{abstract}

$\begin{array}{rr}254 & 244 \\ 41 & 48 \\ 94 & 32 \\ 185 & 187 \\ 10 & 19 \\ 16 & 73 \\ 33 & 45 \\ 4 & 4 \\ 4 & 4 \\ 6 & 8 \\ 2 & 2 \\ 2 & 3 \\ 0 & 8\end{array}$

651

677

$3.4 \%$

$39.0 \%$

$34.7 \%$

$6.6 \%$

$1.8 \%$

$100.0 \%$

$\begin{array}{rr}10.8 \% & 10.5 \% \\ 5.8 \% & 6.3 \% \\ 36.0 \% & 33.1 \% \\ 34.7 \% & 32.5 \% \\ 9.5 \% & 13.1 \% \\ 3.2 \% & 4.5 \% \\ 100.0 \% & 100.0 \%\end{array}$

214
51
12
159
27
27
58
6
68
13
2
2
8

647

Refusal to open-ended question

Random entry point: $\$ 5,000 \$ 50,000 \quad \$ 150,000$

$11.9 \%$

$\begin{array}{rrr}50 & 45 & 33 \\ 10 & 10 & 10 \\ \mathbf{2 6 4} & 21 & 13 \\ 37 & 45 & 35 \\ 3 & 4 & 6 \\ 17 & 247 & 20 \\ 5 & 13 & 7 \\ 0 & 1 & 2 \\ 2 & 5 & \mathbf{2 4 6} \\ 3 & 3 & 4 \\ & & \\ 0 & 1 & 4 \\ 1 & 2 & 3\end{array}$

$\begin{array}{rrr}67.3 \% & 62.2 \% & 64.2 \% \\ 4.8 \% & 6.8 \% & 9.7 \% \\ 12.8 \% & 11.3 \% & 8.6 \% \\ 12.0 \% & 13.9 \% & 11.7 \% \\ 2.0 \% & 4.3 \% & 3.4 \% \\ 1.0 \% & 1.5 \% & 2.3 \% \\ 100.0 \% & 100.0 \% & 100.0 \%\end{array}$

Random entry point: $\$ 5,000 \quad \$ 50,000 \quad \$ 150,000$

$\begin{array}{rrr}304 & 289 & 247 \\ 51 & 58 & 61 \\ 358 & 53 & 25 \\ 222 & 232 & 194 \\ 13 & 23 & 33 \\ 33 & 320 & 47 \\ 38 & 58 & 65 \\ 4 & 5 & 8 \\ 6 & 9 & 314 \\ 9 & 11 & 17 \\ 2 & 2 & 2 \\ 2 & 4 & 6 \\ 1 & 10 & 11 \\ & & \\ 1043 & 1074 & 1030\end{array}$

$\begin{array}{rrr}34.3 \% & 29.8 \% & 30.5 \% \\ 3.9 \% & 6.1 \% & 7.6 \% \\ 29.1 \% & 26.9 \% & 24.0 \% \\ 26.2 \% & 27.0 \% & 24.8 \% \\ 4.9 \% & 7.5 \% & 9.5 \% \\ 1.5 \% & 2.6 \% & 3.7 \% \\ 100.0 \% & 100.0 \% & 100.0 \%\end{array}$

Note: 1) Entry bracket categories are highlighted. 2) "DK/RF to entry-bracket question" is calculated as ratio of the highlighted cell to the total case number. 3) "DK/RF to non-entry-bracket question" is calculated as ratio of all the non-highlighted cells ending in DK/RF to the total case number. 
Panel 6: Bond Holdings

HRS 1998: Value of Bonds Holdings

DK to open-ended question

Random entry point:

Unfolding range

$<\$ 2,500$

About $\$ 2,500$

$\mathrm{DK} / \mathrm{RF}$ if $<>\$ 2,500$

$>\$ 2,500 \&<\$ 10,000$

About $\$ 10,000$

$>\$ 10,000 \&<\$ 100,000$

About $\$ 100,000$

DK/RF if $<>\$ 100,000$

$>\$ 100,000 \&<\$ 400,000$

About $\$ 400,000$

DK/RF if $<>\$ 400,000$

$>\$ 400,000$

Total Case Number
DK/RF if $<>\$ 10,000$

\begin{abstract}
$\$ 2,500 \quad \$ 10,000 \quad \$ 100,000$
\end{abstract}

$\begin{array}{rrr}8 & 6 & 4 \\ 2 & 4 & 1 \\ 14 & 2 & 1 \\ 17 & 12 & 7 \\ 4 & 5 & 3 \\ 2 & 16 & 6 \\ 19 & 29 & 26 \\ 2 & 3 & 2 \\ 5 & 3 & 21 \\ 8 & 5 & 11 \\ 1 & 0 & 0 \\ & & \\ 5 & 1 & 4 \\ 87 & 86 & 86\end{array}$

Percentage Distribution by Bracket Category

DK/RF to entry-bracket question $\quad 16.1 \%$

DK/RF to non-entry-bracket question

$<\$ 2,500$

$>=\$ 2,500 \&<\$ 10,000$

$>=\$ 10,000 \&<\$ 100,000$

$>=\$ 100,000$

Total

$\begin{array}{rrr}16.1 \% & 18.6 \% & 24.4 \% \\ 8.0 \% & 5.8 \% & 8.1 \% \\ 9.2 \% & 7.0 \% & 4.7 \% \\ 21.8 \% & 18.6 \% & 9.3 \% \\ 26.4 \% & 39.5 \% & 33.7 \% \\ 18.4 \% & 10.5 \% & 19.8 \% \\ 100.0 \% & 100.0 \% & 100.0 \%\end{array}$

Refusal to open-ended question

Random entry point: $\$ 2,500 \quad \$ 10,000 \quad \$ 100,000$

Random entry point: $\$ 2,500 \quad \$ 10,000 \quad \$ 100,000$

$\begin{array}{rrr}8 & 6 & 4 \\ 2 & 4 & 2 \\ 43 & 3 & 1 \\ 17 & 12 & 7 \\ 4 & 6 & 3 \\ 4 & 49 & 6 \\ 25 & 32 & 32 \\ 2 & 3 & 2 \\ 5 & 6 & 45 \\ 8 & 5 & 11 \\ 1 & 0 & 0 \\ 0 & 0 & 2 \\ 5 & 2 & 4 \\ 124 & 128 & 119\end{array}$

Note: 1) Entry bracket categories are highlighted. 2) "DK/RF to entry-bracket question" is calculated as ratio of the highlighted cell to the total case number. 3) "DK/RF to non-entry-bracket question" is calculated as ratio of all the non-highlighted cells ending in DK/RF to the total case number. 


\section{Panel 7: CD Holdings}

HRS 1998: Value of CD Accounts Holdings

DK to open-ended question

Random entry point:

Unfolding range

$<\$ 2,500$

About $\$ 2,500$

$\mathrm{DK} / \mathrm{RF}$ if $<>\$ 2,500$

$>\$ 2,500 \&<\$ 25,000$

$\mathrm{DK} / \mathrm{RF}$ if $<>\$ 25,000$

$>\$ 25,000 \&<\$ 125,000$

About $\$ 125,000$

$\mathrm{DK} / \mathrm{RF}$ if $<>\$ 125,000$

$>\$ 125,000 \&<\$ 250,000$

About $\$ 250,000$

$\mathrm{DK} / \mathrm{RF}$ if $<>\$ 250,000$

$>\$ 250,000$

Total Case Number
About $\$ 25,000$

\section{$\$ 2,500 \$ 25,000 \quad \$ 125,000$}

$\begin{array}{rrr}43 & 18 & 17 \\ 7 & 11 & 9 \\ 37 & 3 & 2 \\ 51 & 55 & 41 \\ 4 & 11 & 21 \\ 5 & 44 & 9 \\ 43 & 42 & 50 \\ 7 & 3 & 2 \\ 5 & 5 & 45 \\ 7 & 6 & 6 \\ 2 & 2 & 0 \\ 0 & 0 & 3 \\ 6 & 9 & 4 \\ & & \\ 217 & 209 & 209\end{array}$

Percentage Distribution by Bracket Category

DK/RF to entry-bracket question $\quad 17.1 \%$

DK/RF to non-entry-bracket question

$<\$ 2,500$

$>=\$ 2,500 \&<\$ 25,000$

$>=\$ 25,000 \&<\$ 125,000$

$>=\$ 125,000$

Total

$4.6 \%$
$19.8 \%$
$26.7 \%$
$21.7 \%$
$10.1 \%$
$100.0 \%$

Refusal to open-ended question

Random entry point: $\$ 2,500 \quad \$ 25,000 \quad \$ 125,000$

$\begin{array}{lll}5 & 6 & 1 \\ 1 & 1 & 1\end{array}$

100

6

0

5

6

0

2

0

0

1

128

149

$\begin{array}{rr}78.1 \% & 77.9 \% \\ 6.3 \% & 5.4 \% \\ 3.9 \% & 4.0 \% \\ 5.5 \% & 7.4 \% \\ 4.7 \% & 4.0 \% \\ 1.6 \% & 1.3 \% \\ 00.0 \% & 100.0 \%\end{array}$

$79.4 \%$
$2.8 \%$
$0.7 \%$
$5.7 \%$
$7.1 \%$
$4.3 \%$
$100.0 \%$

Random entry point: $\$ 2,500 \quad \$ 25,000 \quad \$ 125,000$

$\begin{array}{rrr}48 & 24 & 18 \\ 8 & 12 & 10 \\ 137 & 5 & 3 \\ 57 & 65 & 48 \\ 4 & 13 & 22 \\ 10 & 160 & 12 \\ 49 & 46 & 59 \\ 7 & 5 & 3 \\ 7 & 10 & 157 \\ 7 & 6 & 8 \\ 2 & 2 & 1 \\ 1 & 1 & 3 \\ 8 & 9 & 6 \\ 345 & 358 & 350\end{array}$

$44.7 \%$

$4.5 \%$

$6.7 \%$

$21.5 \%$

$16.5 \%$

$6.1 \%$

$100.0 \%$
$44.9 \%$

$5.1 \%$

$5.1 \%$

$16.6 \%$

$23.1 \%$

$5.1 \%$

$100.0 \%$

Note: 1) Entry bracket categories are highlighted. 2) "DK/RF to entry-bracket question" is calculated as ratio of the highlighted cell to the total case number. $3)$ "DK/RF to non-entry-bracket question" is calculated as ratio of all the non-highlighted cells ending in DK/RF to the total case number. 


\section{Panel 8: Vehicle Holdings}

HRS 1998: Value of Vehicles

\section{DK to open-ended question}

Unfolding range

$<\$ 5,000$

About $\$ 5,000$

DK/RF if $<>\$ 5,000$

$>\$ 5,000 \&<\$ 25,000$

About $\$ 25,000$

DK/RF if $<>\$ 25,000$

$>\$ 25,000 \&<\$ 200,000$

About $\$ 200,000$

$\mathrm{DK} / \mathrm{RF}$ if $<>\$ 200,000$

$>\$ 200,000$

Total Case Number

Random entry point: $\$ 5,000 \quad \$ 25,000 \quad \$ 200,000$

$\begin{array}{rrr}257 & 193 & 220 \\ 76 & 84 & 87 \\ \mathbf{8 0} & 22 & 23 \\ 268 & 272 & 230 \\ 19 & 24 & 32 \\ 5 & \mathbf{5 2} & 8 \\ 50 & 66 & 63 \\ 1 & 1 & 3 \\ 0 & 0 & \mathbf{3 2} \\ 2 & 3 & 12 \\ 758 & 717 & 710\end{array}$

Percentage Distribution by Bracket Category

DK/RF to entry-bracket question

$\begin{array}{rrr}10.6 \% & 7.3 \% & 4.5 \% \\ 0.7 \% & 3.1 \% & 4.4 \% \\ 33.9 \% & 26.9 \% & 31.0 \% \\ 45.4 \% & 49.7 \% & 44.6 \% \\ 9.1 \% & 12.6 \% & 13.4 \% \\ 0.4 \% & 0.6 \% & 2.1 \% \\ 100.0 \% & 100.0 \% & 100.0 \%\end{array}$

Refusal to open-ended question

Random entry point: $\$ 5,000 \$ 25,000 \quad \$ 200,000$

Random entry point: $\$ 5,000 \quad \$ 25,000 \quad \$ 200,000$

$\begin{array}{rrr}6 & 1 & 10 \\ 3 & 3 & 3\end{array}$

49

4

0

2

0

0

0

1

8

1
44

2

1

64

61

$7.5 \%$

$\begin{array}{rr}76.6 \% & 72.1 \% \\ 3.1 \% & 1.6 \% \\ 9.4 \% & 1.6 \% \\ 10.9 \% & 18.0 \% \\ 0.0 \% & 4.9 \% \\ 0.0 \% & 1.6 \% \\ 100.0 \% & 100.0 \%\end{array}$

68

$\begin{array}{rrr}263 & 194 & 230 \\ 79 & 87 & 90 \\ 129 & 23 & 23 \\ 272 & 280 & 236 \\ 19 & 25 & 34 \\ 7 & 96 & 11 \\ 50 & 68 & 67 \\ 1 & 2 & 4 \\ 0 & 0 & 71 \\ 2 & 3 & 12 \\ 822 & 778 & 778\end{array}$

$$
\begin{array}{r}
57.4 \% \\
4.4 \% \\
14.7 \% \\
13.2 \% \\
8.8 \% \\
1.5 \% \\
100.0 \%
\end{array}
$$

$68.4 \%$

$\begin{array}{rr}15.7 \% & 12.3 \% \\ 0.9 \% & 3.0 \% \\ 32.0 \% & 24.9 \% \\ 42.7 \% & 47.2 \% \\ 8.4 \% & 12.0 \% \\ 0.4 \% & 0.6 \% \\ 100.0 \% & 100.0 \%\end{array}$

Note: 1) Entry bracket categories are highlighted. 2) "DK/RF to entry-bracket question" is calculated as ratio of the highlighted cell to the total case number. 3) "DK/RF to non-entry-bracket question" is calculated as ratio of all the non-highlighted cells ending in DK/RF to the total case number. 


\section{Panel 9: Other Asset Holdings}

HRS 1998: Value of Other Assets

DK to open-ended question

Random entry point:

Unfolding range

$<\$ 5,000$

About $\$ 5,000$

DK/RF if $<>\$ 5,000$

$>\$ 5,000 \&<\$ 50,000$

About $\$ 50,000$

$\mathrm{DK} / \mathrm{RF}$ if $<>\$ 50,000$

$>\$ 50,000 \&<\$ 100,000$

About $\$ 100,000$

$\mathrm{DK} / \mathrm{RF}$ if $<>\$ 100,000$

$>\$ 100,000$

Total Case Number

Percentage Distribution by Bracket Category

DK/RF to entry-bracket question

$\begin{array}{rrr}15.1 \% & 9.6 \% & 10.7 \% \\ 2.5 \% & 1.9 \% & 7.4 \% \\ 20.2 \% & 13.5 \% & 14.9 \% \\ 42.0 \% & 45.2 \% & 40.5 \% \\ 7.6 \% & 15.4 \% & 13.2 \% \\ 12.6 \% & 14.4 \% & 13.2 \% \\ 100.0 \% & 100.0 \% & 100.0 \%\end{array}$

DK/RF to non-entry-bracket question

$<\$ 5,000$

$>=\$ 5,000 \&<\$ 50,000$

$>=\$ 50,000 \&<\$ 100,000$

$>=\$ 100,000$

Total
Refusal to open-ended question
Random entry point: $\$ 5,000 \quad \$ 50,000 \quad \$ 100,000$

$\begin{array}{rrr}24 & 14 & 18 \\ 11 & 3 & 9 \\ 18 & 2 & 1 \\ 39 & 44 & 40 \\ 6 & 8 & 7 \\ 1 & 10 & 8 \\ 3 & 8 & 9 \\ 2 & 5 & 4 \\ 2 & 0 & 13 \\ 13 & 10 & 12 \\ 119 & 104 & 121\end{array}$

\section{$\$ 5,000 \$ 50,000 \quad \$ 100,000$}

9

4

13

12

Note: 1) Entry bracket categories are highlighted. 2) "DK/RF to entry-bracket question" is calculated as ratio of the highlighted cell to the total case number. 3) "DK/RF to non-entry-bracket question" is calculated as ratio of all the non-highlighted cells ending in DK/RF to the total case number.
Random entry point: $\$ 5,000 \quad \$ 50,000 \quad \$ 100,000$

$\begin{array}{rrr}27 & 15 & 20 \\ 11 & 3 & 9 \\ 44 & 2 & 1 \\ 42 & 47 & 43 \\ 6 & 11 & 7 \\ 4 & 34 & 8 \\ 4 & 10 & 10 \\ 2 & 5 & 4 \\ 2 & 0 & 36 \\ 13 & 10 & 14 \\ 155 & 137 & 152\end{array}$

$100.0 \% \quad 100.0 \% \quad 100.0 \%$

$\begin{array}{rrrrrrr}72.2 \% & 72.7 \% & 74.2 \% & 73.0 \% & 28.4 \% & 24.8 \% & 23.7 \% \\ 8.3 \% & 0.0 \% & 0.0 \% & & 3.9 \% & 1.5 \% & 5.9 \% \\ 8.3 \% & 3.0 \% & 6.5 \% & & 17.4 \% & 10.9 \% & 13.2 \% \\ 8.3 \% & 9.1 \% & 9.7 \% & 34.2 \% & 36.5 \% & 34.2 \% \\ 2.8 \% & 15.2 \% & 3.2 \% & & 6.5 \% & 15.3 \% & 11.2 \% \\ 0.0 \% & 0.0 \% & 6.5 \% & 9.7 \% & 10.9 \% & 11.8 \% \\ 100.0 \% & 100.0 \% & 100.0 \% & 100.0 \% & 100.0 \% & 100.0 \%\end{array}$




\section{Panel 10: Debts}

HRS 1998: Value of Debts

DK to open-ended question

Random entry point:
$\$ 500 \quad \$ 5,000 \quad \$ 50,000$

$<\$ 500$

About $\$ 500$

$\mathrm{DK} / \mathrm{RF}$ if $<>\$ 500$

$>\$ 500 \&<\$ 5,000$

About $\$ 5,000$

$\mathrm{DK} / \mathrm{RF}$ if $<>\$ 5,000$

$>\$ 5,000 \&<\$ 50,000$

About $\$ 50,000$

$\mathrm{DK} / \mathrm{RF}$ if $<>\$ 50,000$

$>\$ 50,000$

Total Case Number

$\begin{array}{rrr}23 & 20 & 4 \\ 7 & 2 & 6 \\ 18 & 2 & 0 \\ 47 & 42 & 38 \\ 15 & 10 & 9 \\ 5 & 24 & 5 \\ 41 & 55 & 41 \\ 2 & 1 & 3 \\ 1 & 1 & 10 \\ 4 & 5 & 5 \\ 163 & 162 & 121\end{array}$

Percentage Distribution by Bracket Category

DK/RF to entry-bracket question $\quad 11.0 \%$

DK/RF to non-entry-bracket question

$<\$ 500$

$>=\$ 500 \&<\$ 5,000$

$>=\$ 5,000 \&<\$ 50,000$

$>=\$ 50,000$

Total

$14.1 \%$

$33.1 \%$

$34.4 \%$

$3.7 \%$

$100.0 \%$
Refusal to open-ended

question

Random entry point:
$\$ 500 \quad \$ 5,000 \quad \$ 50,000$

Random entry point:

$\$ 500 \quad \$ 5,000 \quad \$ 50,000$

$\begin{array}{rrr}1 & 0 & 1 \\ 0 & 1 & 0 \\ \mathbf{1 6} & 1 & 0 \\ 11 & 5 & 5 \\ 1 & 1 & 2 \\ 3 & \mathbf{1 9} & 1 \\ 5 & 4 & 12 \\ & & \\ 0 & 0 & 14 \\ 2 & 1 & 3\end{array}$

$\begin{array}{lll}39 & 32 & 38\end{array}$

38

$\begin{array}{rrr}41.0 \% & 59.4 \% & 36.8 \% \\ 7.7 \% & 3.1 \% & 2.6 \% \\ 2.6 \% & 0.0 \% & 2.6 \% \\ 28.2 \% & 18.8 \% & 13.2 \% \\ 15.4 \% & 15.6 \% & 36.8 \% \\ 5.1 \% & 3.1 \% & 7.9 \% \\ 100.0 \% & 100.0 \% & 100.0 \%\end{array}$

$45.0 \%$

$\begin{array}{rrr}16.8 \% & 22.2 \% & 15.1 \% \\ 4.5 \% & 2.1 \% & 3.8 \% \\ 11.9 \% & 10.3 \% & 3.1 \% \\ 32.2 \% & 25.8 \% & 30.8 \% \\ 30.7 \% & 36.1 \% & 40.3 \% \\ 4.0 \% & 3.6 \% & 6.9 \% \\ 100.0 \% & 100.0 \% & 100.0 \%\end{array}$

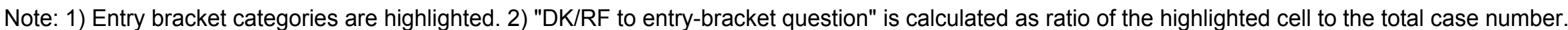

3 ) "DK/RF to non-entry-bracket question" is calculated as ratio of all the non-highlighted cells ending in DK/RF to the total case number. 


\section{Appendix 3}

Distribution of HRS 1998 sample by unfolding bracket Range, Entry Point, and whether DK or REF in Response to questions about Asset holdings (unweighted dollars)

\section{Panel 1: Value of Real Estate Holdings}

HRS 1998: Value of Real Estate Holdings

DK to open-ended question

Unfolding range
$<\$ 2,500$
About $\$ 2,500$
DK/RF if $<>\$ 2,500$
$>\$ 2,500 \&<\$ 125,000$
About $\$ 125,000$
DK/RF if $<>\$ 125,000$
$>\$ 125,000 \&<\$ 500,000$
About $\$ 500,000$
DK/RF if $<>\$ 500,000$
$>\$ 500,000 \&<\$ 1,000,000$
About $\$ 1,000,000$
DK/RF if $<>\$ 1,000,000$
$>\$ 1,000,000$

All Categories

\begin{tabular}{rrr}
\multicolumn{3}{c}{ Random entry point: } \\
$\$ 2,500$ & $\$ 125,000$ & $\$ 500,000$ \\
& & \\
1,178 & 771 & 856 \\
2,500 & 2,500 & 2,500 \\
197,188 & 67,000 & 30,857 \\
43,182 & 40,872 & 43,746 \\
125,000 & 125,000 & 125,000 \\
175,667 & 104,196 & 72,000 \\
196,552 & 232,500 & 245,361 \\
500,000 & 500,000 & 500,000 \\
492,975 & 300,000 & 126,882 \\
626,250 & 709,091 & 662,500 \\
$1,000,000$ & $1,000,000$ & $1,000,000$ \\
. & 725,000 & 750,000 \\
$2,065,500$ & $1,562,500$ & $3,062,500$ \\
& & \\
168,006 & 201,647 & 238,348
\end{tabular}

Refusal to open-ended question

\begin{tabular}{rrr}
\multicolumn{3}{c}{ Random entry point: } \\
$\$ 2,500$ & $\$ 125,000$ & $\$ 500,000$ \\
& & \\
1,000 &. & 1,000 \\
. &. &. \\
185,500 &. & 55,000 \\
28,833 & 40,000 & 38,333 \\
125,000 &. & 125,000 \\
275,000 & 183,304 & 49,667 \\
. & 250,000 &. \\
. &. &. \\
100,000 & 420,000 & 318,786 \\
. & 750,000 & 800,000 \\
. &. &. \\
. & $1,875,000$ &. \\
$2,000,000$ &. & $3,000,000$ \\
238,630 & 325,667 & 337,039
\end{tabular}

Random entry point: $\$ 2,500 \quad \$ 125,000 \quad \$ 500,000$

$\begin{array}{rrr}1,160 & 771 & 870 \\ 2,500 & 2,500 & 2,500 \\ \mathbf{1 9 2 , 1 7 9} & 67,000 & 36,222 \\ 42,623 & 40,859 & 43,484 \\ 125,000 & 125,000 & 125,000 \\ 200,500 & 142,909 & 64,556 \\ 196,552 & 234,444 & 245,361 \\ 500,000 & 500,000 & 500,000 \\ 414,380 & 348,000 & \mathbf{2 1 3 , 5 4 8} \\ 626,250 & 712,500 & 677,778 \\ 1,000,000 & 1,000,000 & 1,000,000 \\ . & 1,300,000 & 750,000 \\ 2,043,667 & 1,562,500 & 3,050,000 \\ & & \\ 176,087 & 222,209 & 252,369\end{array}$


Panel 2: Business/Farm Asset Holding

HRS 1998: Business/Farm Asset Holding

DK to open-ended question

\begin{tabular}{lrrr} 
& \multicolumn{3}{c}{ Random entry point: } \\
Unfolding range & $\$ 5,000$ & $\$ 10,000$ & $\$ 100,000$ \\
& & & \\
$<\$ 5,000$ & 346 & 0 & 0 \\
About $\$ 5,000$ & 5,000 & 5,000 & 5,000 \\
DK/RF if $<>\$ 5,000$ & $\mathbf{1 8 6 , 6 0 0}$ &. &. \\
$>$ >5,000 \& $<\$ 10,000$ & 6,667 & 8,600 & 8,500 \\
About $\$ 10,000$ & 10,000 & 10,000 & 10,000 \\
DK/RF if $<>\$ 10,000$ & 98,333 & $\mathbf{3 4 4 , 7 0 1}$ & 10,000 \\
$>$ >10,000 \& $<\$ 100,000$ & 47,667 & 42,880 & 48,250 \\
About $\$ 100,000$ & 100,000 & 100,000 & 100,000 \\
DK/RF if $<>\$ 100,000$ & $1,256,000$ & 520,000 & $\mathbf{2 1 9 , 3 0 0}$ \\
$>$ >100,000 \& $<\$ 1,000,000$ & 344,091 & 291,487 & 288,333 \\
About $\$ 1,000,000$ & $1,000,000$ & $1,000,000$ & $1,000,000$ \\
DK/RF if $<>\$ 1,000,000$ & 500,000 & 700,000 & \\
$>$ > $\$ 1,000,000$ & $2,816,667$ & $4,066,667$ & $1,920,000$ \\
& & & \\
All Categories & 253,451 & 319,421 & 327,271
\end{tabular}

Refusal to open-ended question

Random entry point:

$\$ 5,000 \quad \$ 10,000 \quad \$ 100,000$

$\begin{array}{rrr}\text { r. } & . & . \\ 5,000 & . & . \\ 285,648 & . & . \\ . & . & . \\ 10,000 & . & . \\ 50,000 & 157,893 & . \\ 43,333 & 65,000 & 18,500 \\ . & 100,000 & . \\ 668,667 & 1,000,000 & 181,386 \\ 450,000 & 233,333 & . \\ . & . & . \\ 300,000 & 500,000 & 900,000 \\ . & . & 2,500,000 \\ & & \\ 284,836 & 223,500 & 285,673\end{array}$

Random entry point: $\$ 5,000 \quad \$ 10,000 \quad \$ 100,000$

$\begin{array}{rrr}346 & 0 & 0 \\ 5,000 & 5,000 & 5,000 \\ \mathbf{2 3 1 , 8 1 8} & . & 8,500 \\ 6,667 & 8,600 & .000 \\ 10,000 & 10,000 & 10,000 \\ 86,250 & 272,053 & 10,000 \\ 47,273 & 44,519 & 46,267 \\ 100,000 & 100,000 & 100,000 \\ 1,035,750 & 580,000 & 203,260 \\ 352,917 & 287,333 & 288,333 \\ 1,000,000 & 1,000,000 & 1,000,000 \\ 400,000 & 566,667 & 900,000 \\ 2,816,667 & 4,066,667 & 1,972,727 \\ & & \\ 260,090 & 304,713 & 319,963\end{array}$




\section{Panel 3: IRA - 1 Holdings}

HRS 1998: IRA - 1 Holdings

DK to open-ended question

Random entry point:

Unfolding range

$<\$ 10,000$

About $\$ 10,000$

$\mathrm{DK} / \mathrm{RF}$ if $<>\$ 10,000$

$>\$ 10,000 \&<\$ 25,000$

About $\$ 25,000$

$\mathrm{DK} / \mathrm{RF}$ if $<>\$ 25,000$

$>\$ 25,000 \&<\$ 100,000$

About $\$ 100,000$

$\mathrm{DK} / \mathrm{RF}$ if $<>\$ 100,000$

$>\$ 100,000 \&<\$ 400,000$

About $\$ 400,000$

$\mathrm{DK} / \mathrm{RF}$ if $<>\$ 400,000$

$>\$ 400,000$

All Categories
$\$ 10,000 \quad \$ 25,000 \quad \$ 100,000$

$\begin{array}{rrr}4,545 & 4,874 & 4,312 \\ 10,000 & 10,000 & 10,000 \\ \mathbf{5 4 , 0 9 0} & 8,900 & 4,000 \\ 16,972 & 16,954 & 15,818 \\ 25,000 & 25,000 & 25,000 \\ 61,111 & \mathbf{4 8 , 5 6 6} & 35,769 \\ 52,633 & 48,969 & 50,789 \\ 100,000 & 100,000 & 100,000 \\ 127,000 & 85,500 & \mathbf{5 5 , 2 7 5} \\ 194,191 & 183,947 & 230,762 \\ 400,000 & . & 400,000 \\ 300,000 & 115,000 & 230,000 \\ 955,667 & 557,500 & 1,250,000 \\ & & \\ 75,337 & 56,988 & 68,907\end{array}$

Refusal to open-ended

question

Random entry point:

$\$ 10,000 \$ 25,000 \quad \$ 100,000$

$\begin{array}{rrr}5,383 & 5,117 & 3,260 \\ 10,000 & . & 10,000 \\ 46,951 & 10,667 & 9,500 \\ 16,850 & 17,000 & 17,500 \\ 25,000 & 25,000 & 25,000 \\ 115,530 & \mathbf{8 2 , 5 2 5} & 23,446 \\ 46,333 & 50,941 & 53,783 \\ . & . & . \\ 94,571 & 53,750 & \mathbf{5 4 , 6 5 3} \\ 151,066 & 118,200 & 240,625 \\ . & 400,000 & . \\ 120,000 & 801,667 & 175,000 \\ 587,500 & . & 708,333 \\ & & \\ 60,933 & 87,735 & 70,114\end{array}$

Random entry point: $\$ 10,000 \quad \$ 25,000 \quad \$ 100,000$

$\begin{array}{rrr}4,713 & 4,905 & 4,158 \\ 10,000 & 10,000 & 10,000 \\ \mathbf{4 9 , 2 7 4} & 9,657 & 6,750 \\ 16,960 & 16,960 & 16,267 \\ 25,000 & 25,000 & 25,000 \\ 89,753 & \mathbf{7 1 , 7 6 3} & 29,608 \\ 51,233 & 49,364 & 51,599 \\ 100,000 & 100,000 & 100,000 \\ 109,539 & 69,625 & \mathbf{5 4 , 8 9 2} \\ 185,897 & 170,250 & 233,483 \\ 400,000 & 400,000 & 400,000 \\ 210,000 & 527,000 & 202,500 \\ 863,625 & 557,500 & 925,000 \\ & & \\ 70,034 & 67,835 & 69,378\end{array}$


Panel 4: Value of Stock Holdings

HRS 1998: Value of Stock Holdings

\section{DK to open-ended question}

\begin{tabular}{lrrr} 
& \multicolumn{3}{c}{ Random entry point: } \\
Unfolding range & $\$ 2,500$ & $\$ 25,000$ & $\$ 125,000$ \\
& & & \\
$<\$ 2,500$ & 992 & 1,152 & 918 \\
About $\$ 2,500$ & 2,500 & 2,500 & 2,500 \\
DK/RF if $<>\$ 2,500$ & 275,373 & 8,509 & 625 \\
$>$ > $2,500 \&<\$ 25,000$ & 10,310 & 11,002 & 11,319 \\
About $\$ 25,000$ & 25,000 & 25,000 & 25,000 \\
DK/RF if <> \$25,000 & 52,842 & $\mathbf{8 9 , 9 1 0}$ & 35,385 \\
$>$ > $25,000 \&<\$ 125,000$ & 61,485 & 65,400 & 62,167 \\
About $\$ 125,000$ & 125,000 & 125,000 & 125,000 \\
DK/RF if <> \$125,000 & 211,100 & 155,000 & $\mathbf{9 3 , 5 6 7}$ \\
$>$ >125,000 \& $<\$ 400,000$ & 203,333 & 210,699 & 216,667 \\
About $\$ 400,000$ & & 400,000 & 400,000 \\
DK/RF if <> $\$ 400,000$ & 368,571 & 250,000 & 320,000 \\
$>$ > 400,000 & $1,225,294$ & $2,112,000$ & $1,504,332$ \\
& & & \\
All Categories & 154,286 & 207,181 & 158,936
\end{tabular}

Refusal to open-ended question

\begin{tabular}{rrr}
\multicolumn{3}{c}{ Random entry point: } \\
$\$ 2,500$ & $\$ 25,000$ & $\$ 125,000$ \\
& & \\
1,100 &. &. \\
. &. &. \\
131,395 & 6,000 &. \\
7,500 & 11,630 & 10,333 \\
25,000 & 25,000 & 25,000 \\
103,455 & 116,733 & 17,500 \\
49,143 & 63,500 & 66,111 \\
125,000 &. & 125,000 \\
323,343 & 204,444 & 135,315 \\
146,000 & 200,000 & 196,200 \\
. & 400,000 & \\
. & 325,000 & 388,571 \\
$2,177,322$ & 700,000 & 570,000 \\
& & \\
174,773 & 139,999 & 156,573
\end{tabular}

Random entry point: $\$ 2,500 \quad \$ 25,000 \quad \$ 125,000$

$\begin{array}{rrr}997 & 1,152 & 918 \\ 2,500 & 2,500 & 2,500 \\ \mathbf{1 9 7 , 1 4 9} & 8,123 & 625 \\ 10,058 & 11,064 & 11,239 \\ 25,000 & 25,000 & 25,000 \\ 77,048 & \mathbf{1 0 5 , 0 4 1} & 34,107 \\ 60,215 & 65,087 & 62,505 \\ 125,000 & 125,000 & 125,000 \\ 237,002 & 176,191 & \mathbf{1 1 5 , 4 5 9} \\ 201,286 & 209,709 & 213,138 \\ . & 400,000 & 400,000 \\ 368,571 & 287,500 & 360,000 \\ 1,368,098 & 1,847,250 & 1,343,240 \\ & & \\ 159,048 & 189,612 & 158,384\end{array}$




\section{Panel 5: Value of Checking and Savings Accounts Holdings}

HRS 1998: Value of Checking and Savings Accounts Holdings

\begin{tabular}{|c|c|c|c|}
\hline \multirow[b]{3}{*}{ Unfolding range } & \multicolumn{3}{|c|}{ DK to open-ended question } \\
\hline & \multicolumn{3}{|c|}{ Random entry point: } \\
\hline & $\$ 5,000$ & $\$ 50,000$ & $\$ 150,000$ \\
\hline$<\$ 5,000$ & 1,531 & 1,532 & 1,506 \\
\hline About $\$ 5,000$ & 5,000 & 5,000 & 5,000 \\
\hline$D K / R F$ if $<>\$ 5,000$ & 15,085 & 8,477 & 7,550 \\
\hline$>\$ 5,000 \&<\$ 50,000$ & 17,264 & 17,226 & 16,901 \\
\hline About $\$ 50,000$ & 50,000 & 50,000 & 50,000 \\
\hline$D K / R F$ if $<>\$ 50,000$ & 33,000 & 30,456 & 18,268 \\
\hline$>\$ 50,000 \&<\$ 150,000$ & 77,545 & 77,378 & 81,783 \\
\hline About $\$ 150,000$ & 150,000 & 150,000 & 150,000 \\
\hline$D K / R F$ if $<>\$ 150,000$ & 122,500 & 352,500 & 15,492 \\
\hline$>\$ 150,000 \&<\$ 300,000$ & 223,500 & 204,625 & 209,539 \\
\hline About $\$ 300,000$ & 300,000 & 300,000 & 300,000 \\
\hline$D K / R F$ if $<>\$ 300,000$ & 200,000 & 211,333 & 212,500 \\
\hline$>\$ 300,000$ & & 521,091 & 531,250 \\
\hline All Categories & 18,777 & 29,263 & 30,748 \\
\hline
\end{tabular}

Refusal to open-ended question

$$
\text { Random entry point: }
$$
$\$ 5,000 \$ 50,000 \quad \$ 150,000$

$\begin{array}{rrr}1,516 & 1,359 & 1,717 \\ 5,000 & 5,000 & 5,000 \\ \mathbf{1 6 , 4 1 8} & 10,293 & 7,835 \\ 16,216 & 20,322 & 17,031 \\ 50,000 & 50,000 & 50,000 \\ 35,900 & \mathbf{1 9 , 8 1 8} & 16,430 \\ 85,000 & 80,923 & 97,623 \\ . & 150,000 & 150,000 \\ 332,500 & 79,200 & \mathbf{3 0 , 3 7 6} \\ 225,000 & 233,333 & 216,000 \\ . & . & \\ . & 175,000 & 196,750 \\ 330,000 & 425,000 & 500,000 \\ & & \\ 20,193 & 24,332 & 34,047\end{array}$

Random entry point: $\$ 5,000 \quad \$ 50,000 \quad \$ 150,000$

$\begin{array}{rrr}1,529 & 1,505 & 1,534 \\ 5,000 & 5,000 & 5,000 \\ \mathbf{1 6 , 0 6 8} & 9,197 & 7,698 \\ 17,090 & 17,826 & 16,924 \\ 50,000 & 50,000 & 50,000 \\ 34,494 & \mathbf{2 2 , 2 4 4} & 17,486 \\ 78,526 & 78,172 & 83,489 \\ 150,000 & 150,000 & 150,000 \\ 192,500 & 200,667 & \mathbf{2 7 , 1 5 2} \\ 224,000 & 212,455 & 211,059 \\ 300,000 & 300,000 & 300,000 \\ 200,000 & 202,250 & 202,000 \\ 330,000 & 501,873 & 522,727 \\ & & \\ 19,309 & 27,440 & 31,975\end{array}$




\section{Panel 6: Value of Bonds Holdings}

HRS 1998: Value of Bonds Holdings

DK to open-ended question

Random entry point:

Unfolding range

$<\$ 2,500$

About $\$ 2,500$

DK/RF if $<>\$ 2,500$

$>\$ 2,500 \&<\$ 10,000$

About $\$ 10,000$

DK/RF if $<>\$ 10,000$

$>\$ 10,000 \&<\$ 100,000$

About $\$ 100,000$

DK/RF if $<>\$ 100,000$

$>\$ 100,000 \&<\$ 400,000$

About \$400,000

DK/RF if $<>\$ 400,000$

$>\$ 400,000$

All Categories

$\$ 2,500 \$ 10,000 \quad \$ 100,000$

$\begin{array}{rrr}900 & 1,267 & 875 \\ 2,500 & 2,500 & 2,500 \\ \mathbf{4 3 , 6 4 3} & 1,250 & 9,000 \\ 5,088 & 5,833 & 5,429 \\ 10,000 & 10,000 & 10,000 \\ 85,500 & \mathbf{8 0 , 5 6 3} & 37,333 \\ 39,932 & 38,293 & 33,577 \\ 100,000 & 100,000 & 100,000 \\ 75,200 & 298,333 & \mathbf{8 1 , 0 9 0} \\ 169,375 & 227,000 & 222,727 \\ 400,000 & . & . \\ . & . & . \\ 680,000 & 700,000 & 625,000 \\ 85,177 & 64,763 & 93,406\end{array}$

Refusal to open-ended question

Random entry point: $\$ 2,500 \quad \$ 10,000 \quad \$ 100,000$

$\begin{array}{rrr}\cdot & . & . \\ . & . & 2,500 \\ 161,452 & 300,000 & . \\ . & . & . \\ . & 10,000 & . \\ 55,000 & 98,903 & . \\ 23,917 & 33,333 & 30,333 \\ . & . & . \\ . & 35,000 & 69,133 \\ . & . & . \\ . & . & . \\ . & . & 158,000 \\ . & 500,000 & . \\ & & 65,445\end{array}$

Random entry point: $\$ 2,500 \quad \$ 10,000 \quad \$ 100,000$

$\begin{array}{rrr}900 & 1,267 & 875 \\ 2,500 & 2,500 & 2,500 \\ 123,095 & 100,833 & 9,000 \\ 5,088 & 5,833 & 5,429 \\ 10,000 & 10,000 & 10,000 \\ 70,250 & 92,914 & 37,333 \\ 36,088 & 37,828 & 32,969 \\ 100,000 & 100,000 & 100,000 \\ 75,200 & 166,667 & 74,713 \\ 169,375 & 227,000 & 222,727 \\ 400,000 & . & \\ . & . & 158,000 \\ 680,000 & 600,000 & 625,000 \\ & & 85,652\end{array}$




\section{Panel 7: Value of CD Accounts Holdings}

HRS 1998: Value of CD Accounts Holdings

DK to open-ended question

\begin{tabular}{lrrr} 
& \multicolumn{3}{c}{ Random entry point: } \\
Unfolding range & $\$ 2,500$ & $\$ 25,000$ & $\$ 125,000$ \\
& & & \\
$<\$ 2,500$ & 1,074 & 1,406 & 1,341 \\
About $\$ 2,500$ & 2,500 & 2,500 & 2,500 \\
DK/RF if $<>\$ 2,500$ & $\mathbf{4 0 , 5 0 8}$ & 13,667 & 11,025 \\
$>$ \$2,500 \& $<\$ 25,000$ & 12,131 & 11,655 & 10,220 \\
About $\$ 25,000$ & 25,000 & 25,000 & 25,000 \\
DK/RF if $<>\$ 25,000$ & 71,400 & $\mathbf{3 4 , 1 6 1}$ & 41,617 \\
$>$ \$25,000 \& $<\$ 125,000$ & 56,814 & 67,762 & 61,180 \\
About $\$ 125,000$ & 125,000 & 125,000 & 125,000 \\
DK/RF if <> \$125,000 & 50,000 & 89,200 & $\mathbf{4 5 , 0 9 2}$ \\
$>$ >125,000 \& $<\$ 250,000$ & 177,143 & 184,333 & 187,500 \\
About $\$ 250,000$ & 250,000 & 250,000 & \\
DK/RF if $<>\$ 250,000$ &. &. & 250,000 \\
$>$ >250,000 & 318,333 & 380,562 & 387,500 \\
& & & \\
All Categories & 45,420 & 53,641 & 48,560
\end{tabular}

Refusal to open-ended question

\begin{tabular}{rrr}
\multicolumn{3}{c}{ Random entry point: } \\
$\$ 2,500$ & $\$ 25,000$ & $\$ 125,000$ \\
& & \\
1,500 & 1,200 & 2,400 \\
2,500 & 2,500 & 2,500 \\
46,899 & 1,000 & 10,000 \\
9,667 & 11,600 & 11,000 \\
. & 25,000 & 25,000 \\
22,200 & 39,445 & 63,333 \\
64,167 & 57,500 & 62,444 \\
. & 125,000 & 125,000 \\
35,500 & 44,000 & 49,457 \\
. &. & 165,000 \\
. &. & 250,000 \\
200,000 & 300,000 & \\
37,500 &. & 400,000 \\
& & \\
48,437 & 38,613 & 56,122
\end{tabular}

Random entry point:

$\$ 2,500 \quad \$ 25,000 \quad \$ 125,000$

$\begin{array}{rrr}1,119 & 1,354 & 1,400 \\ 2,500 & 2,500 & 2,500 \\ \mathbf{4 5 , 1 7 3} & 8,600 & 10,683 \\ 11,872 & 11,646 & 10,333 \\ 25,000 & 25,000 & 25,000 \\ 46,800 & \mathbf{3 7 , 9 9 2} & 47,046 \\ 57,714 & 66,870 & 61,373 \\ 125,000 & 125,000 & 125,000 \\ 45,857 & 66,600 & \mathbf{4 8 , 2 0 6} \\ 177,143 & 184,333 & 181,875 \\ 250,000 & 250,000 & 250,000 \\ 200,000 & 300,000 & 250,000 \\ 323,125 & 380,562 & 391,667 \\ & & \\ 46,539 & 47,386 & 51,606\end{array}$


Panel 8: Value of Vehicles

HRS 1998: Value of Vehicles

\begin{tabular}{|c|c|c|c|}
\hline \multirow[b]{3}{*}{ Unfolding range } & \multicolumn{3}{|c|}{ DK to open-ended question } \\
\hline & \multicolumn{3}{|c|}{ Random entry point: } \\
\hline & $\$ 5,000$ & $\$ 25,000$ & $\$ 200,000$ \\
\hline$<\$ 5,000$ & 1,900 & 1,861 & 1,935 \\
\hline About $\$ 5,000$ & 5,000 & 5,000 & 5,000 \\
\hline DK/RF if <> $\$ 5,000$ & 10,334 & 8,823 & 9,683 \\
\hline$>\$ 5,000 \&<\$ 25,000$ & 12,404 & 13,044 & 13,262 \\
\hline About $\$ 25,000$ & 25,000 & 25,000 & 25,000 \\
\hline DK/RF if $<>\$ 25,000$ & 35,800 & 10,354 & 14,650 \\
\hline$>\$ 25,000 \&<\$ 200,000$ & 50,040 & 47,545 & 44,532 \\
\hline About $\$ 200,000$ & 200,000 & 200,000 & 200,000 \\
\hline$D K / R F$ if $<>\$ 200,000$ & & & 9,248 \\
\hline$>\$ 200,000$ & 250,000 & 416,667 & 248,333 \\
\hline All Categories & 11,709 & 14,292 & 16,524 \\
\hline
\end{tabular}

Refusal to open-ended question

Random entry point:

$\$ 5,000 \quad \$ 25,000 \quad \$ 200,000$

$\begin{array}{rrr}1,250 & 500 & 2,405 \\ 5,000 & 5,000 & 5,000 \\ \mathbf{1 2 , 2 2 0} & 0 & . \\ 14,500 & 11,125 & 13,867 \\ . & 25,000 & 25,000 \\ 13,500 & \mathbf{1 8 , 8 6 4} & 9,533 \\ . & 30,000 & 40,000 \\ . & 200,000 & 200,000 \\ . & . & \mathbf{1 6 , 8 8 5} \\ . & . & . \\ 11,036 & 19,992 & 17,932\end{array}$

Random entry point: $\$ 5,000 \quad \$ 25,000 \quad \$ 200,000$

$\begin{array}{rrr}1,885 & 1,854 & 1,956 \\ 5,000 & 5,000 & 5,000 \\ \mathbf{1 1 , 0 5 1} & 8,439 & 9,683 \\ 12,435 & 12,989 & 13,277 \\ 25,000 & 25,000 & 25,000 \\ 29,429 & \mathbf{1 4 , 2 5 4} & 13,255 \\ 50,040 & 47,029 & 44,261 \\ 200,000 & 200,000 & 200,000 \\ . & . & \mathbf{1 3 , 4 4 3} \\ 250,000 & 416,667 & 248,333\end{array}$

$11,656 \quad 14,739 \quad 16,647$ 
Panel 9: Value of Other Assets

HRS 1998: Value of Other Assets

\begin{tabular}{lrrr} 
& DK to open-ended question \\
& \multicolumn{3}{c}{ Random entry point: } \\
Unfolding range & $\$ 5,000$ & $\$ 50,000$ & $\$ 100,000$ \\
& & & \\
$<\$ 5,000$ & 2,188 & 1,891 & 2,169 \\
About $\$ 5,000$ & 5,000 & 5,000 & 5,000 \\
DK/RF if $<>\$ 5,000$ & $\mathbf{2 0 , 1 1 1}$ & 8,500 & 5,000 \\
$>$ > $\$ 5,000 \&<\$ 50,000$ & 14,518 & 20,750 & 19,530 \\
About $\$ 50,000$ & 50,000 & 50,000 & 50,000 \\
DK/RF if $<>\$ 50,000$ & 150,000 & $\mathbf{5 8 , 5 0 0}$ & 15,188 \\
$>$ >50,000 \& $<\$ 100,000$ & 75,000 & 69,375 & 68,778 \\
About $\$ 100,000$ & 100,000 & 100,000 & 100,000 \\
DK/RF if $<>\$ 100,000$ & 80,000 &. & $\mathbf{3 2 , 0 9 2}$ \\
$>$ > $\$ 100,000$ & 285,462 & 191,000 & 267,667 \\
& & & \\
All Categories & 48,586 & 47,322 & 49,504
\end{tabular}

Refusal to open-ended question

Random entry point: $\$ 5,000 \quad \$ 50,000 \quad \$ 100,000$

$\begin{array}{rrr}2,318 & 3,000 & 1,313 \\ . & . & . \\ 44,385 & . & . \\ 20,000 & 19,000 & 21,667 \\ . & 50,000 & . \\ 20,000 & 63,875 & . \\ 85,000 & 68,500 & 0 \\ . & . & . \\ . & . & 45,735 \\ . & . & 147,500 \\ 37,943 & 56,970 & 45,630\end{array}$

Random entry point: $\$ 5,000 \quad \$ 50,000 \quad \$ 100,000$

$\begin{array}{rrr}2,202 & 1,965 & 2,084 \\ 5,000 & 5,000 & 5,000 \\ \mathbf{3 4 , 4 5 5} & 8,500 & 5,000 \\ 14,910 & 20,638 & 19,679 \\ 50,000 & 50,000 & 50,000 \\ 52,500 & \mathbf{6 2 , 2 9 4} & 15,188 \\ 77,500 & 69,200 & 61,900 \\ 100,000 & 100,000 & 100,000 \\ 80,000 & . & \mathbf{4 0 , 8 0 9} \\ 285,462 & 191,000 & 250,500 \\ & & \\ 46,114 & 49,646 & 48,714\end{array}$




\section{Panel 10: Value of Debts}

HRS 1998: Value of Debts

DK to open-ended question

\begin{tabular}{lrrr} 
& \multicolumn{3}{c}{ Random entry point: } \\
Unfolding range & $\$ 500$ & $\$ 5,000$ & $\$ 50,000$ \\
& & & \\
$<\$ 500$ & 193 & 234 & 182 \\
About $\$ 500$ & 500 & 500 & 500 \\
DK/RF if $<>\$ 500$ & $\mathbf{8 , 5 7 3}$ & 600 &. \\
$>$ \$500 \& $<\$ 5,000$ & 1,989 & 1,979 & 1,929 \\
About $\$ 5,000$ & 5,000 & 5,000 & 5,000 \\
DK/RF if $<>\$ 5,000$ & 3,400 & $\mathbf{4 , 6 8 9}$ & 5,500 \\
$>$ > $5,000 \&<\$ 50,000$ & 14,988 & 14,661 & 13,929 \\
About $\$ 50,000$ & 50,000 & 50,000 & 50,000 \\
DK/RF if $<>\$ 50,000$ & 6,000 & 20,000 & $\mathbf{4 , 6 1 0}$ \\
$>$ >50,000 & 57,250 & 103,002 & 73,600 \\
& & & \\
All Categories & 7,959 & 10,147 & 10,618
\end{tabular}

Refusal to open-ended question

\begin{tabular}{rrr}
\multicolumn{3}{c}{ Random entry point: } \\
$\$ 500$ & $\$ 5,000$ & $\$ 50,000$ \\
& & \\
100 &. & 400 \\
. & 500 &. \\
$\mathbf{8 , 6 9 5}$ & 4,000 &. \\
1,814 & 1,900 & 1,660 \\
5,000 & 5,000 & 5,000 \\
1,333 & 18,271 & 20,000 \\
13,200 & 14,500 & 11,808 \\
. &. &. \\
. &. & 13,079 \\
125,000 & 100,000 & $469,000^{a}$ \\
& & \\
12,415 & 16,380 & $35,175^{a}$
\end{tabular}

Random entry point:

$$
\$ 500 \quad \$ 5,000 \quad \$ 50,000
$$

$\begin{array}{lll}190 & 234 & 225\end{array}$

$500 \quad 500 \quad 500$

$\begin{array}{llr}\mathbf{8 , 6 3 1} & 1,733 & \text {. } \\ 1,956 & 1,970 & 1,898\end{array}$

$5,000 \quad 5,000 \quad 5,000$

$2,625 \quad 10,690 \quad 7,917$

$14,793 \quad 14,650 \quad 13,449$

$50,000 \quad 50,000 \quad 50,000$

$6,000 \quad 20,000 \quad \mathbf{9 , 5 5 0}$

$79,833 \quad 102,502 \quad 186,571^{a}$

$8,819 \quad 11,175 \quad 16,388^{\mathrm{a}}$

Note: ${ }^{a}$ One imputed outlier $(6,666,733)$ was removed from the calculation. 


\section{Appendix 4}

Mean Asset Values Associated with Different Entry Points: Owners Only

\begin{tabular}{|l|c|c|c|}
\hline Asset & Low Entry Point & Middle Entry Point & High Entry Point \\
\hline Real Estate & 176,087 & 222,209 & 252,369 \\
\hline Business/Farm & 260,090 & 304,713 & 319,963 \\
\hline IRAs & 70,034 & 67,835 & 69,378 \\
\hline Stock & 159,048 & 189,612 & 158,384 \\
\hline Chk/Sav/MM & 19,309 & 27,440 & 31,975 \\
\hline Bonds & 99,564 & 76,941 & 85,652 \\
\hline CDs, T-Bills & 46,539 & 47,386 & 51,606 \\
\hline Vehicles & 11,656 & 14,739 & 16,647 \\
\hline Other Assets & 46,114 & 49,646 & 48,714 \\
\hline Debt & 8,819 & 11,175 & 16,388 \\
\hline TOTAL & $\mathbf{8 7 8 , 6 2 2}$ & $\mathbf{9 8 9 , 3 4 6}$ & $\mathbf{1 , 0 1 8 , 3 0 0}$ \\
\hline $\begin{array}{l}\text { \% increase between entry } \\
\text { groups }\end{array}$ & -- & $\mathbf{1 2 . 6 \%}$ & $\mathbf{2 . 9 \%}$ \\
\hline
\end{tabular}

Note: "Total" and "\% increase between entry groups" are statistics that may not be sensible conceptually. We include them here only for crude cross-entry-point comparisons.

This table provides an overview of the relation between entry point and mean value of assets. The data are restricted to asset owners, and summarize the mean value of owner assets by entry point. Although the general pattern is that higher entry points are associated with larger means, which is what entry point bias would expect, there are many exceptions to that generalization. For example, while Real Estate, Business/Farm, and checking/savings/money market accounts have the relationship expected by entry point bias, IRAs and Bonds have the largest mean in the lowest entry point group, and stocks have the highest mean in the middle entry point group. As a gross overall measure, the percentage difference in the mean between the middle and high entry point groups is a miniscule $2.9 \%$. 